\title{
Large-scale response of the Eastern Mediterranean thermohaline circulation to African monsoon intensification during sapropel $\mathbf{S 1}$ formation
}

\author{
Tesi T. ${ }^{1}{ }^{*}$, Asioli A. ${ }^{2}$, Minisini D. ${ }^{3}$, Maselli V. ${ }^{4}$, Valle G. Dalla ${ }^{1}$, Gamberi F. ${ }^{1}$, Langone L. ${ }^{1}$, \\ Cattaneo Antonio ${ }^{5}$, Montagna P. ${ }^{1}$, Trincardi F. ${ }^{1}$
}

${ }^{1}$ CNR, CNR ISMAR, Ist Sci Marine, Via Gobetti 101, I-40129 Bologna, Italy.

2 CNR, IGG, Via G Gradenigo 6, I-35131 Padua, Italy.

${ }^{3}$ Shell Int Explorat \& Prod Inc, 3333 Highway 6 South, Houston, TX 77082 USA.

4 Univ Aberdeen, Dept Geol \& Petr Geol, Kings Coll, St Marys Bldg, Aberdeen AB24 3UF, Scotland.

5 IFREMER, Geosci Marines EDROME, Ctr Brest, BP70, F-29280 Plouzane, France.

*Corresponding author : T. Tesi, email address : tommaso.tesi@bo.ismar.cnr.it

\begin{abstract}
:
The formation of Eastern Mediterranean sapropels has periodically occurred during intensification of northern hemisphere monsoon precipitation over North Africa. However, the large-scale response of the Eastern Mediterranean thermohaline circulation during these monsoon-fuelled freshening episodes is poorly constrained. Here, we investigate the formation of the youngest sapropel (S1) along an acrossslope transect in the Adriatic Sea. Foraminifera-based oxygen index, redox-sensitive elements and biogeochemical parameters reveal - for the first time - that the Adriatic S1 was synchronous with the deposition of south-eastern Mediterranean S1 beds. Proxies of paleo thermohaline currents indicate that the bottom-hugging North Adriatic Dense Water (NAdDW) suddenly decreased at the sapropel onset simultaneously with the maximum freshening of the Levantine Sea during the African Humid Period. We conclude that the lack of the "salty" Levantine Intermediate Water hampered the preconditioning of the northern Adriatic waters necessary for the NAdDW formation prior to the winter cooling. Consequently, a weak NAdDW limited in turn the Eastern Mediterranean Deep Water (EMDWAdriatic) formation with important consequences for the ventilation of the Ionian basin as well. Our results highlight the importance of the Adriatic for the deep water ventilation and the interdependence among the major eastern Mediterranean water masses whose destabilization exerted first-order control on S1 deposition.
\end{abstract}




\section{Highlights}

- The Adriatic S1 is coeval with the Eastern Mediterranean S1 deposits. The Adriatic S1 onset is synchronous with the shutdown of the NAdDW. African monsoons weakened the LIW which in turn hampered the NAdDW formation.

Keywords : Sapropel S1, Mediterranean sea, African monsoons, Anoxia, Thermohaline circulation 


\section{Introduction}

Periodic perturbations of marine ecology and geochemistry have occurred in the eastern 55 Mediterranean Sea (EMS) since the late Miocene (Nijenhuis et al., 1996). Signs of these changes are 56 preserved in the sediment record as organic carbon-rich deposits commonly known as sapropels. In this 57 study we focus on the most recent sapropel (S1) which formed during the last post-glacial eustatic rise (ca. 58 10-6 cal kyr BP (De Lange et al., 2008; Hennekam et al., 2014; Schmiedl et al., 2010). It is now largely 59 accepted (Rohling et al., 2015)_that favourable conditions for S1 formation were associated with anoxic

60 bottom waters that developed during periods of insolation maxima (Hilgen, 1991; Rossignol-Strick, 1985;

61 Rossignol-Strick et al., 1982). The resulting effect of these orbital variations was the northward migration 62 of the African monsoons resulting in higher precipitation over the Nile river watershed which in turn 63 enhanced the freshwater supply to the EMS- southeastern Mediterranean Sea (Hennekam et al., 2014;

64 Weldeab et al., 2014). In addition, the mid-Holocene increase of river runoff from northern borderlands 65 and the post-glacial inflow of less saline Atlantic waters have further contributed to maintaining reduced 66 surface water salinities and high nutrient concentrations in the euphotic zone (Grimm et al., 2015; 67 Kotthoff et al., 2008; Spötl et al., 2010; Toucanne et al., 2015). To date, whether and to what degree either 68 water stratification or enhanced primary productivity has resulted in anoxic bottom waters is still a matter 69 of debate despite several decades of extensive study (Calvert et al., 1992; De Lange et al., 2008; Grimm et 70 al., 2015; Sachs and Repeta, 1999).

71 A survey of the current literature dealing with S1 reveals that most of the focus has been placed on 72 south-eastern Mediterranean sediments while the Adriatic Sea - that today plays a first-order control on 73 Eastern Mediterranean ventilation (Klein et al., 2000) - has received markedly less interest. In particular, 
74 it has been suggested (Rohling et al., 1997; Rohling et al., 2015) that the onset of critical oxygen 75 conditions in the Adriatic (ca. 8.8 cal. ky BP) lagged behind the fairly synchronous anoxia which 76 developed over the rest of the EMS (ca. 10 cal. ky BP)_(De Lange et al., 2008; Schmiedl et al., 2010). This

77 implies that the ventilation regime under which the Adriatic sapropel formed must have been necessarily 78 different compared to the south-eastern Mediterranean sapropels. In particular, it was inferred that 79 persistent ventilation in the Adriatic during the early stage of the-sapropel formation hampered the initial 80 development of oxygen-depleted conditions justifying the delayed S1 onset in respect to the rest of the 81 EMS (Mercone et al., 2000; Rohling et al., 2015).

82 This high-resolution (decadal-millenniatcentennial) study aims at testing this hypothesis by 83 reconstructing the oceanographic regime under which Adriatic sapropels formed. -Our analysis builds on 84 three well-dated sediment cores collected in three different water depths from the shelf to the deep basin 85 (Fig. 1 and 2). With the objective of understanding timing and conditions which promoted anoxic bottom 86 waters, we present a suite of complementary analyses which include foraminifera assemblages, inorganic 87 elemental composition and organic matter composition. The relatively young age of S1 makes it an ideal 88 target to develop a precise radiocarbon-based Bayesian age model across the three sites establishing also a 89 robust chronological link to other S1 depestisdeposits across the EMS. Thus, by identifying coeval and 90 genetically linked depositsstrata, we will evaluate the necessary conditions leading to the sapropel S1 91 formation in Adriatic sediments and test to what extent these prerequisites are linked to the deposition of 92 sapropel beds in the rest of the EMS.

\section{2. Material and methods}

\section{$95 \quad 2.1$ Sediment cores}

The dataset presented here consists of three piston cores retrieved in the Adriatic Sea with variable 97 barrel lengths (5-20 m) (Fig.1 and 2). Core AMC99-1 (4551'.80 N \& 14 45'.68 E, 260 m; Fig. 1) was 98 collected in the central Adriatic basin from the bottom of the mid-Adriatic depression (MAD, Fig. 2b). 

$17^{\circ} 10^{\prime} .78 \mathrm{E}, 567 \mathrm{~m}$ ) were collected $5 \mathrm{~m}$ apart from each other (i.e., twin cores; Fig. 1 and $2 \mathrm{c}$ ) in the

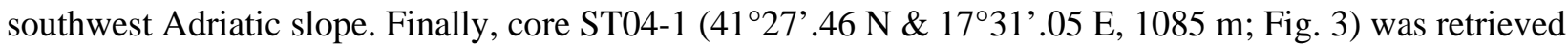
in the deep basin plain of the south-western Adriatic Sea (Fig. 1 and Fig. 2c).

\subsection{Seismic acquisition and core handling}

The seismic dataset used in this study has been collected by ISMAR-CNR (Bologna) on board R/V Urania, in the last two decades. Seismic data were acquired with a hull-mounted Chirp-Sonar Profiler with 16 transducers, characterized by $2-7 \mathrm{kHz}$ sweep-modulated bandwidth, equivalent to a $3.5 \mathrm{kHz}$ profiler, with a recording length up to $1500 \mathrm{~ms}$, depending on water depth, and a penetration of 50-100 m, with vertical resolution of ca. $0.5 \mathrm{~m}$. Track line positioning was based on differential GPS navigation, assuring

110 a position accuracy of $10 \mathrm{~m}$ and transformed to geographic coordinates referred to the ED-50 datum.

\section{$112 \quad$ 2.3 Digital x-ray radiograph}

113 Prior to subsampling, cores were x-rayed using a Gilardoni MPX160 as a source and an amorphous $30 \mathrm{~cm}$ 114 long silicon (a-Si) flat panel sensor as a detector (Kodak) typically exposed at $70 \mathrm{kV}$ and $5 \mathrm{~mA}$ for ca. 6.4 s. For each digital image the pixel dimension is $125 \mu \mathrm{m}$ and resolution is $1932 \times 2348$ pixels.

\section{3-4 Foraminifera}

Sediment samples (1-cm thick interval) were oven dried at $50^{\circ} \mathrm{C}$, washed through a $63 \mu \mathrm{m}$ sieve and were counted to reach at least 300 specimens of planktonic foraminifera and 300 specimens of benthic

121 foraminifera. In anoxic beds only planktonic foraminifera were observed. The quantitative study was 122 performed on the fraction $>1 \underline{06} 60 \mu \mathrm{m}$ to avoid juvenile specimens, consistent with the existing Adriatic 
123 literature (Favaretto et al., 2008; Narciso et al., 2012; Piva et al., 2008). However, the <160 $\mu \mathrm{m}$ fraction 124 was always checked in order to identify those specimens which can pass the mesh because of an elongated 125 shape of their shell (e.g. Fursenkoina) or because of the small size of their adult stage (e.g. Epistominella). $126-$ Foraminifera concentration is reported as the number of specimens per gram of dry sediment. Data 127 were then integrated with previous published studies (core SA03-1 and AMC99-1; (Favaretto et al., 2008; 128 Narciso et al., 2012; Piva et al., 2008)) to gain higher resolution within the time interval studied. 129 Specifically, twenty-two new samples from SA03-01 were merged with published data (Favaretto et al., 130 2008; Narciso et al., 2012) while 42 new samples from core AMC99-1 were integrated with data 131 published (Piva, 2007; Piva et al., 2008). Finally, fifty-three samples of core INVAS12-10 were examined 132 with a semi-quantitative analysis to identify key levels (bioevents) for stratigraphic and chronologic 133 purposes (i.e., correlation with the sister core SA03-1), as all geochemical analyses were performed on 134 core INVAS12-10.

The Oxygen Index (OI) (Schmiedl et al., 2003) was used to provide a general trend of bottom oxygen conditions. It is calculated as $(\mathrm{HO} /(\mathrm{HO}+\mathrm{LO})+\mathrm{Div}) \times 0.5$ where $\mathrm{HO}$ is the relative abundance of high oxygen indicators (Miliolids, Articulina tubulosa+Cibicidoides pachydermus+Gyroidinoides 138 orbicularis), LO is the relative abundance of low oxygen indicators (Fursenkoina spp., Chilostomella 139 oolina, Globobulimina spp.), and Div is the normalized benthic foraminiferal diversity H(S). The term is 140 multiplied by 0.5 to distinguish between anoxic (minimum value $=0$ ) and oxic (maximum value $=1$ ) 141 conditions (Schmiedl et al., 2010; Schmiedl et al., 2003). The index has been calculated for cores ST04-1 142 and SA03-1, while for core AMC99-1 the term LO (=species of the group A by (Jorissen, 1999) with a 143 deep infaunal microhabitat, especially resistant to low oxygen conditions), has been replaced by the 144 infaunal benthonic taxa of the group B by Jorissen (1999), that is Bolivina spp/Brizalina spp, Bulimina 145 costata/ inflata and Uvigerina peregrina, with an infaunal microhabitat, more opportunistic than the 146 species of group A, but less resistant for low oxygen conditions (Schmiedl et al., 2003) because deep 147 infaunal species were absent, or near-absent, during the time equivalent to the Sapropel 1a deposition, as 
148 already reported in the central Adriatic by Ariztegui et al. (2000). The absence/near-absence of species of

149 the LO term would have resulted into not realistic values indicating highly oxygenated bottom condition

150 in the OI index during the Sapropel 1a interval, making necessary the use of the abundant taxa of group B.

$151 \quad$ Reworked species used as bottom current proxy include the modern living inner-shelf species such

152 as Ammonia spp, Elphidium spp, Haynesina spp. and epiphyitic species (Asterigerinata spp, Buccella

153 granulata, Patellina corrugata) (Jorissen, 1988) corresponding to Biofacies II and III in the Adriatic. We

154 interpret the presence of these displaced species by sediment shedding from shallower waters (Trincardi et

155 al., 2007), in particular from outer-shelf coarser/sandy (Spagnoli et al., 2010) deposits formed during the

156 LGM and presently swept by NAdDW. The Oxygen Index (Schmiedlet al., 2003) has been calculated for

157 cores ST04 1 and SAO3-1, while for core AMC99 1 the term LO (=low oxygen indicators, correspending

158 to the deep infaunal benthønic species (Jorissen, 1999)) has been replaced by infaunal benthønic species

159 (Bolivina spp/Brizalina spp, Bulimina costatalinflata and Uvigerina peregrina) (Schmiedl et al., 2003) as

160 deep infaunal species were absent.Reworked species used as bottom current proxy include Ammonia spp,

161 Elphidium spp, and epifiticepiphytic species corresponding to Biofacies II and III in Adriatic (Jorissen,

162 1988).-We interpret the presence of these displaced species by sediment shedding from shallower waters

163 (Trincardi et al., 2007), in particular from outer-shelf coarser/sandy (Spagnoli et al., 2010) deposits

164 formed during the LGM and presently swept by NAdDW.

165 Reworked species used as bottom current proxy include the modern living inner-shelf species such

166 as Ammonia spp, Elphidium spp, Haynesina spp. and epifitic species (Asterigerinata spp, Buccella

167 granulata, Patellina corrugata)-(Jorissen, 1988) corresponding to Biofacies II and III in the Adriatic. We

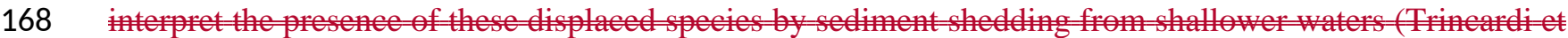

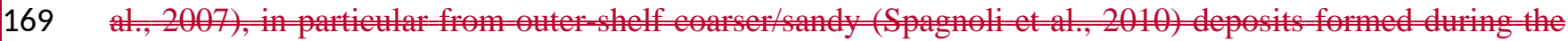

170 EGM and padPently

Radiocarbon measurements on monospecific tests (5-7 $\mathrm{mg}$ ) of the planktonic foraminifer

172 Globigerinoides ruber (species living above the thermocline) were performed at the National Ocean 
173 Sciences Accelerator Mass Spectrometry (NOSAMS) Facility (USA). On average, 400-600 specimens 174 were hand-picked from the size fraction $>0.180 \mu \mathrm{mm}$. Specimens were ultrasonicated in distilled water to 175 remove potential sediment impurities. For level ST040-1 XII 61-62 cm, the planktonic foraminifer 176 Globorotalia inflata was used due to the lack of a sufficient amount of G. ruber specimens.

\section{$178 \quad 2.6-5$ X-ray fluorescence (XRF)}

The inorganic composition of bulk sediments was characterized using a wavelength dispersive 180 sequential Philips PW2400 XRF spectrometer (Mercone et al., 2001) (at the-Department of Geosciences, 181 (University of Padova). The XRF instrument was operated under vacuum conditions on samples prepared 182 as glass beads using lithium tetraborate and melted with a fluxer Claisse Fluxy $\left(\sim 1150^{\circ} \mathrm{C}\right)$. The standard 183 error (based on several measurements of the same sample) is less than $0.6 \%$ and $3 \%$ for major element and 184 trace elements, respectively. For this study, we focused on selected elements which include Ti, V, Mn and 185 S.. Sediments corresponding to tephra layers (characterized by high Zr excess) were analyzed but the data 186 are not shown.

\section{7 $\underline{6}$ Grain-size}

About $3 \mathrm{~g}$ of dried sediments were resuspended in a $40 \mathrm{ml}$ solution of sodium metaphosphate $190(0.6 \%)$ and sonicated for 20 minutes at high energy. Prior to the analysis, samples $\mathrm{A}$ were wet sieved at 63 $191 \mu \mathrm{m}$. A few drops of wet samples were checked with the microscope to examine the presence of 192 microfossil remains. PParticle size distribution of the $<63 \mu \mathrm{m}$ fraction was measured using a 193 Micromeritics SediGraph ${ }^{\mathrm{TM}}$ III 5120- according to the settling velocity method (Bianchi et al., 1999). 194 Sortable silt concentration was calculated as the fraction by weight of the total mass ranging between 10 195 and $63 \mu \mathrm{m}$ (McCave and Hall, 2006). 
220 (Table 1).

\section{8-7_Organic Geochemistry}

Samples for organic carbon (OC) content were placed in silver capsules and pre-treated with $\mathrm{HCl}$ (1.5 M) to remove the inorganic carbon_(Nieuwenhuize et al., 1994). Oven-dry samples were analysed using a Thermo Quest-Finnigan Delta Plus isotope ratio mass spectrometer, directly coupled to a FISONS NA2000 Elemental Analyzer by means of a CONFLO II interface.

Lignin analyses (terrigenous biomarkers) were carried out using a Microwave digestion system (Tesi et al., 2014). Dry samples were placed in Teflon vessels with $8 \mathrm{ml}$ of alkaline solution $(2 \mathrm{~N} \mathrm{NaOH})$, $500 \mathrm{mg}$ of $\mathrm{CuO}, 50 \mathrm{mg}$ of $\mathrm{Fe}\left(\mathrm{NH}_{4}\right) 2\left(\mathrm{SO}_{4}\right) 2 \cdot 6 \mathrm{H}_{2} \mathrm{O}$ and oxidized for $1.5 \mathrm{~h}$ at $150{ }^{\circ} \mathrm{C}$. After the oxidation, a known amount of recovery standards (ethylvanillin and trans-cinnamic acid) were added to each vessel and acidified to $\mathrm{pH} 1$ with $\mathrm{HCl}$. Reaction products were then extracted with ethyl acetate, evaporated to dryness under $\mathrm{N}_{2}$ and redissolved in pyridine. Reaction products were analysed as trimethylsilyl derivatives (BSTFA reagent) via GC-MS. Compounds were separated chromatographically in a $30 \mathrm{~m} \times 250$ $\mu \mathrm{m}$ DB1 $\left(0.25 \mu \mathrm{m}\right.$ film thickness) capillary GC column, using an initial temperature of $100{ }^{\circ} \mathrm{C}$, a temperature ramp of $4{ }^{\circ} \mathrm{C} \min ^{-1}$ and a final temperature of $300{ }^{\circ} \mathrm{C}$. Phenol biomarkers were quantified using the response factors of commercially available standards (Tesi et al., 2014).

\section{Chronology}

\subsection{Age-depth models}

Bayesian age-depth models were performed using the OxCal 4.2 program (https://c14.arch.ox.ac.uk/embed.php?File=oxcal.html) and a comprehensive dataset, which includes both ${ }^{14} \mathrm{C}$ measurements carried out on monospecific foraminifera samples (this study) as well as radiocarbondated bioevents based on a detailed event biostratigraphy from each sediment core (Fig. 4 and 5). Radiocarbon age (uncalibrated) of well-known bioevents was based on published studies in the Adriatic 

planktonic assemblage turnovers (Fig. 4 and Table 1):

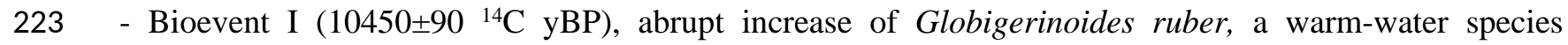
224 signalingsignalling the top of the Younger Dryas dated in core CM92-43 (Asioli et al., 2001). This 225 bioevent marks the end of the Greenland Stadial 1 (GS1) and the beginning of the Holocene (top ecozone 226 V) (Asioli et al., 2001; Asioli et al., 1999; Blockley et al., 2004) and also the top of ecozone 7_(Siani et al., 227 2010). The GS-1/Holocene transition is also testified by the lowering of the $\delta^{18} \mathrm{O}$ values (Asioli et al., 228 1999; Jorissen et al., 1993; Narciso et al., 2012; Siani et al., 2000);

229 - Bioevents II and III $\left(9860 \pm 60\right.$ and $9360 \pm 50{ }^{14} \mathrm{C}$ yBP, respectively), two peaks in the abundance of 230 Globorotalia inflata (i.e., younger and older). These bioevents were described and dated in core SA03-1 231 (Favaretto et al., 2008) before its temporary disappearance at the base of the Sapropel S1;

232 - Bioevent IV $\left(5880 \pm 60{ }^{14} \mathrm{C}\right.$ yBP), last Occurrence of G. inflata dated in core RF93-30_(Trincardi et al., 233 1996). This is a well-documented bioevent recognized in the whole Adriatic after the sapropel 234 S1termination (Ariztegui et al., 2000; Asioli et al., 1999; Capotondi et al., 1999; Siani et al., 2010). using the latest Marine13 calibration curve (Reimer et al., 2013) in OxCal, prior to calibration, ages were corrected for an extra $136 \pm 41{ }^{14} \mathrm{C}$-years regional reservoir effect $(\Delta \mathrm{R})$ using the values reported in the 238 Marine Reservoir Correction Database (http://calib.qub.ac.uk/marine/). --Above the sapropel unit $(<5 \mathrm{kyr})$, 239 the age-depth model of AMC99-1 relays on benthic monospecific tests (Cibicidoides pachyderma). For 240 this reason, Only for core AMC99-1 and above the sapropel deposit, $\triangle \mathrm{R}$ was set 336 \pm 41 an extra 200 241 years of reservoir correction was used for these for radiocarbon ages Cibicidoides pachyderma (benthic 242 species) based-according to on the difference-offset between planktonic and benthonic organisms 243 previously assessed in this core_(Piva et al., 2008). Bayesian age-depth model (Lowe et al., 2007; Ramsey, 1995; Ramsey and Lee, 2013) was implemented using variable rigidity for the Poisson-Process Modeling 245 ( $k$ variable ranging between 0.01 and $100 \mathrm{~cm}^{-1}$ ). The Outlier-Model analysis was performed with the 
246 General setting and the prior probability fixed to 0.05 , which weighs down the radiocarbon measurement 247 that have statistical probability of more than $5 \%$ of being outliers. The output resulted in robust age 248 models with an overall solid structure of the dated sequence (Fig. 5) as defined by an excellent agreement 249 index (>90\%) between calibrated and modelled ages.

250 It is worth mentioning that foraminifera assemblages were studied in SA03-1 core while the rest of 251 the analyses were performed on the sister core INVAS12-10 from the same site (Fig. 1 and 2c) on which 252 we have constructed the age-depth model based on a greater number of radiocarbon measurements. Cross253 correlation between twin cores was carried out relaying on bioevents and tephra (magnetic susceptibility 254 anomalies). Events in chronological order include: top of the Younger Dryas, two G. inflata peaks (during 255 the Pre Boreal), peak of C. bradyi, a large magnetic susceptibility peak marking a tephra layer, two $G$. 256 inflata peaks (during S1 break and S1b, respectively) and the Llast Occurrence of G. inflata (Fig. 4). Ages 257 between midpoints were estimated via linear interpolation. al., 1999; Giunta et al., 2003; Sangiorgiet al., 2003) (Fig. 6A). Here, prior to presenting and discussing the data, we compare our record from the same region with these published records from the stratigraphic 265 point of view. For the comparison, we selected five main widespread bioevents commonly observed in the 266 Adriatic Sea (Fig. 6B) (Asioli et al., 1999; Narciso et al., 2012; Piva et al., 2008; Rohling et al., 1997;

267 Santacroce et al., 2008; Trincardi et al., 1996). Bioevents include:

268 bioevent I (top GS-1/YD): abrupt increase of G. ruber

269 bioevent II: older peak of $G$. inflata

270 bioevent III: younger peak of $G$. inflata 
271 G. ruber maximum peak of frequency in S1a

272 Globoturborotalita rubescens peak in S1a

273

274 Among these cores, IN68-9 core (i.e., core 362 in previous publications (Van Straaten, 1970) is

275 particularly relevant because our current understanding of the S1 onset is largely based on this record

276 (Rohling et al., 1997; Rohling et al., 2015). IN68-9 was collected at $1234 \mathrm{~m}$ water depth (Fig. 11A) and all

277 the aforementioned biostratigraphic events (source PANGEA, doi:10.1594/PANGAEA.407648) are

278 present and stratigraphically coherent with ST04-1 (bioevent I corresponds in this core to the ecozones I/II

279 boundary) (Fig. 6B). Another similarity includes the ash layer at $\mathrm{cm}$ 128 130. Geochemical analysis

280 defined this event as Mercato tephra (Calanchi and Dinelli, 2008) which is positioned just below the

281 increase of G. rubescens.

282

Despite the overall coherence between IN68-9 and ST04-1 from a stratigraphy point of view,

283 bioevents in IN68-9 exhibit a much younger age compared ST04 1, especially within S1a. To further

284 investigate this discrepancy, we performed a new picking of planktonic foraminifera directly on IN68-9

285 elose to the $G$. ruber peak $(137-138 \mathrm{~cm})$. It was possible to date this interval in core IN68-9 because two-

286 thirds of the original core are currently stored at ISMAR Bologna. The new radiocarbon date (9030 \pm 30 yr

287 BP, uncalib; NOSAMS WHOI; Table S1) turned out much older than the age assessed with the previous

288 age depth model (ca. 8110 yr BP ${ }^{14} \mathrm{C}$ age) but remarkably consistent with the chronology of ST04 1.

The reason for this offset (ca. 1000 y) between the new radiocarbon date and the previous age-depth model (Rohling et al., 1997) is unknown and falls outside the scope of this manuscript. However, it is

291 worth mentioning that the age-depth model of IN68-9 within the S1 interval essentially relies only on two 292 radiocarbon dates (Rohling et al., 1997). We can only suppose that the problem might derive from the 293 lowest radiocarbon date $\left(155.5-157.5 \mathrm{~cm}, 9280 \pm 180\right.$ yBP $\left.{ }^{44} \mathrm{C}\right)$ which is somehow erroneously too young. 294 In fact, this interval roughly corresponds to bioevent II which is again much younger (ca. 1000 years) 295 when compared with our record. Furthermore, this offset is conservative considering that this radiocarbon 
296 test at $155.5-157.5 \mathrm{~cm}$ corresponds to a mixture of benthic foraminifera (Jorissen et al., 1993). Thus, at 297 most, the radiocarbon date should have been older rather than younger. (G. ruber, G. inflata and Globigerinita glutinata) were vistally extrapolated based on the plot of planktonic species is age previously published (Siani et al., 2010). For this core only two bioevents of core ST04-1 were recognized: Bioevent I and II. The G. ruber peak is present but it is coeval with the tephra layer E1 (Gabellotto-Fimmebianco) located close to the S1 interruption and proved to be younger than Mercato tephra (Caron et al., 2012; Marchini et al., 2014). What is striking about this core is the relatively lower thickness of S1a compared to S1b which is unusual for S1 (Mercone et al., 2001; Mercone et al., 2000). This might reflect either a condensed interval or a hiatus above the $G$. glutinata peak. To test this hypothesis, we compared the V/Al record that displays a large peak right after the S1 onset in both Adriatic basin (ST04-1) and slope (INVAS12-10) (Fig 6C). This peak is also well present in other southeastern S1 deposits (e.g., LC21, Aegean Sea (Mercone et al., 2001). The XRF analyses were performed every $\mathrm{cm}$ in MD90-197. However, despite the high resolution, the V/Al peak is not visible (Mercone et al., 2001) (Fig. 12C)

312 foraminifera and monospecific tests (Mercone et al., 2000) reveals a drastic drop in sedimentation rate 313 where the V/Al is expected. This suggests once again either a condensed unit or a hiatus. Even considering 314 the error associated with pulling together monospecific radiocarben tests and mixed planktonic species 315 (these latter integrate the signal of a thicker water column), the apparent drop of sedimentation seems to 316 be still evident in the radiocarbon data (Mercone et al., 2000). Unfortunately, benthic foraminifera are not 317 available for MD90-197 which hampers the direct comparison with ST04-1. For example, the C. bradyi 318 observed in both ST04-1 and IN68-9 at the base of S1 a could have provided additional important clues.

319 Finally, core AD91-17 was collected at 844 m water depth. Two curves of planktic foraminifers (G. ruber 320 and G. inflata) were reported in Fig. 64 based on previous studies (Capotondi et al., 1999). A recent study 
321 showed that the Mercato tephra in this core is present in correspondence of the S1 onset (Marchini et al.,

322 2014). However, Mercato is stratigraphically positioned ca. in the middle of Sla above the G. ruber peak

323 in both IN68-9 and ST04-1, this implies that the lower part of S1a is not present. Indeed, just below

324 Mereato, previous publications have highlighted the presence of a turbidite (Giunta et al., 2003).

326 Finally, core AD91-17, collected at 844 m water depth (6A), records the Sapropel 1 deposition between $327 \mathrm{em} 190$ and 125 (Giunta et al., 2003, Marchini et al., 2014). Two curves of planktic foraminifers (G. ruber 328 and G. inflata) were reported in Fig. 6A based on previous studies (Capotondi et al., 1999). 329 Tephrostratigraphy of this core shows that the sapropel onset $(190-191 \mathrm{~cm})$ correspended to upper limit of 330 Mereato tephra (Marchini et al., 2014). However, Mercato tephra is stratigraphically positioned ca. in the 331 middle of S1a, above the G. ruber peak in IN68-9 (Calanchi and Dinelli, 2008; Rohling et al., 1997) and 332 in ST041. The faet that this G. ruber positioned peak below Mereato is not visible in AD91-17 (Fig. 6A) 333 suggests that the lower portion of the S1a is missing. In fact, previous publications have highlighted the 334 presence of a turbidite just below Mercato between $\mathrm{cm} 200$ and 196 (Giunta et al., 2003) which further 335 support the hypothesis of the stratigraphic gap.

\section{Results and discussion}

\section{$338 \quad 4.1$ Coeval sapropel deposits cross-margin settings}

In this study we present data from sediment cores retrieved in three different regions of the

340 Adriatic Sea: (i) the mid-Adriatic depression (MAD), (ii) the south-western continental slope and (iii) the 341 southern deep basin (Figs. 1 and 2). The mid-Adriatic depression represents a small remnant basin, which 342 was partially filled with sediment during the last glacial maximum (core AMC99-1, $260 \mathrm{~m}$ (Piva et al., 343 2008); Fig. 2b). High-resolution chirp-sonar profile across the coring site shows continuous and high344 amplitude sub-parallel reflectors, which denote sedimentation in low-energy conditions. 
The slope coring site is characterized by large-scale bottom-current deposits formed by prolonged 346 activity of the thermohaline circulation (core INVAS12-10 and SA03-1, from 570 and 567 m respectively 347 (Minisini et al., 2006) (;Fig. 2c). On chirp profiles, these deposits are organized in fields of large sediment 348 waves characterized by wavy and high-amplitude reflectors (Fig. 2c). The coring site was selected on the 349 depositional (up-current) flank of one sediment wave.

350 Finally, the coring site in the southern Adriatic deep basin is characterized by pelagic sedimentation as shown by sub-parallel reflectors, although dense NAdDW can occasionally reach and 352 impact this area (ST04-1, 1085 m_Minisini et al. (2006); Fig. 2d).

Despite the different bathymetric contexts, radiocarbon dates from monospecific tests indicated 354 that these three records represent coeval deposits within the time interval under examination (Table 1). 355 Detailed biostratigraphy examination for all three cores revealed the occurrence of bioevents commonly 356 observed in the study region, which were used to independently test the stratigraphic continuity of our 357 records (Fig. 4). High-resolution Bayesian ${ }^{14} \mathrm{C}$-based age-depth models confirmed continuous deposition 358 consistent with bioevents and seismic profiles (Fig. 5).

\subsection{Adriatic Sapropel deposition}

\subsubsection{Pre-sapropel and S1 onset}

Sapropels are beds with elevated organic carbon (OC) content that contrast with overlying and underlying sediments. In this study, S1 boundaries are defined based on the OC anomalies in respect to the background level. The definition of sapropels can further extend to anomalies of several other parameters including $\mathrm{Ba} / \mathrm{Ti}$ ratio, redox sensitive elements, foraminifera assemblages and magnetic susceptibility or

366 simply changes in sediment colour (De Lange et al., 2008; Mercone et al., 2000; Rohling et al., 1997; 367 Santvoort et al., 1997; Schmiedl et al., 2010; Tachikawa et al., 2015; Vigliotti et al., 2008). Here, we will 368 also discuss these other parameters alongside along the OC data in order to provide a multifaceted view on 369 S1 formation. 
371 gradual OC increase since 11 cal. ky BP before the typical sapropel onset (ca. 10 cal. ky BP) (Hennekam 372 et al., 2014; Rohling et al., 2015; Schmiedl et al., 2010). This trend is consistent with the foraminifera373 based oxygen index (Schmiedl et al., 2010) (OI) which reveals a pre-sapropel deterioration of pore374 waterbottom oxygen levels in the deep basin since ca. 11 cal. ky BP (Fig. 8a-7a and Fig. 9a $\underline{8 a}$ ). Analogous 375 pre-sapropel conditions, ascribed to stratification have recently been documented in the deep Levantine 376 basin at $1780 \mathrm{~m}$ water depth using a suite of redox-sensitive elements (Tachikawa et al., 2015). Post377 glacial freshening driven by the inflow of less saline Atlantic waters via the Gibraltar strait followed by 378 the African Humid Period have certainly exerted a major control on the surface water stratification, 379 vertical mixing and hence intermediate and deep water formation (Rohling et al., 2015; Weldeab et al., 380 2014). (Rogerson et al., 2008)This is also-in line with recent regional simulations which described a 381 gradual deterioration of the deep water ventilation in the EMS since the Heinrich-1 event (H1, ca. 18-16 cal ky BP) (Grimm et al., 2015). Enhanced stratification since the H1 event was one of the major drivers that promoted the formation of organic rich layers (ORLs) in the Alboran Sea (Rogerson et al., 2008). In this western Mediterranean region, the continental run-off due to Alpine glacier thawing (i.e., enhanced $\underline{\text { Rhone river discharge) combined with the Atlantic inflow likely weakened the Western Mediterranean }}$ Deep Water ventilation promoting the deposition of ORLs (Rogerson et al., 2008).

The onset of relatively high OC content which marks the beginning of the Adriatic S1 (i.e, S1a) was synchronous among our records and it was dated around $10 \mathrm{cal}$ ky BP in-across the allthree sites (Fig. $3897 \underline{6} \mathrm{a}, \mathrm{b}, \mathrm{c})$. After this coeval OC increase, the deep Adriatic basin (ST04-1) rapidly turned into an azoic 390 environment (Fig. 9a8a). Specifically, as the pore water oxygen decreased in the basin (Fig. 8a), only 391 infaunal foraminifera could initially tolerate oxygen-poor conditions although the benthic environment 392 rapidly became hostile even for deep infaunal taxa (Fig. $9 \underline{b} \underline{8 b}$ ). Azoic conditions in the basin are marked 393 also by authigenic vanadium enrichments $\left(\mathrm{V} / \mathrm{TiO}_{2}\right.$; Fig. $\left.9 \mathrm{~b} \underline{8 \mathrm{~b}}\right)$ as commonly observed in sapropel beds 394 (Mercone et al., 2001; Tachikawa et al., 2015). Vanadium precipitation is expected in highly reducing 
diffusion processes across the sediment-water interface (Mercone et al., 2000). Sulphur enrichment

$397\left(\mathrm{~S} / \mathrm{TiO}_{2}\right)$ in sapropel beds - likely in the form of authigenic pyrite (Passier et al., 1997) - further

398 corroborates the change of redox conditions characterized by microbial-driven sulfate reduction in 399 response to the oxygen-poor environment (Fig. 10-9 d, e, f).

\subsubsection{Sapropel break, sapropel S1b and sapropel termination}

An interruption within the sapropel unit is visible in our records between ca. 7.8 and $8.3 \mathrm{cal} \mathrm{ky}$ BP. During the break both $\mathrm{OC}$ content and $\mathrm{V} / \mathrm{TiO}_{2}$ decreased while the OI increased indicating a temporary re-oxygenation at the seabed (Fig 7aaa, b, c; Fig 87). The overall trend observed here has been documented in several other S1 deposits further south-east and down to ca. 1,800 m water depth (De Lange et al., 2008; Tachikawa et al., 2015). Reactivation of the convective overturn driven by heat loss during cooling events in the northern Adriatic has been suggested as the most likely scenario to explain the temporary re-oxygenation (Marino et al., 2009; Rohling et al., 1997). The interruption was particularly evident over basin and slope sediments while in the shallower mid-Adriatic slope basin did not display significant change over the break. Already being an oxic environment, it is likely that the mid-Adriatic depression (AMC99-1) was not particularly affected by the temporary resumption of the ventilation.

After the sapropel break, the second phase of S1 deposition (i.e., S1b) lasted for ca. $1 \mathrm{ky}$. Both

$413 \mathrm{~V} / \mathrm{Ti}$ ratio and oxygen index indicate that the reducing conditions during S1b were not as severe in slope 414 sediments as during S1a (Fig. $8-7$ c c, d). This is also consistent with the presence of relatively lower 415 authigenic sulphur content, which suggests comparatively lower sulphate reduction rates during S1b (Fig. 416 10-9 d, e, f). By contrast, the deep southern basin became azoic again for ca. $500 \mathrm{yr}$ (Fig. $8 \mathrm{a} 7 \mathrm{a}$ and $8 \mathrm{a}$ ).

The transitory reappearance of benthic foraminifera and high OI value around $7.4 \mathrm{cal} \mathrm{ky}$ BP in the 418 deep basin (ST04-1) suggests another short-lived ventilation event within the S1b (Fig. 78a) prior to the 419 S1 termination. This was a rather short-lived event but widespread over the EMS as previously observed 420 in the Aegean and Ionian regions (Filippidi et al., 2016). 
422 fairly synchronous among our records according to the OC anomalies (ca. 6.8 cal ky BP, Fig. 7- $\underline{6}$ a,b,c). 423 However, the OI displayed a bathymetric gradient (Fig. \&a7a, b, c) consistent with what observed in the 424 Levantine and Aegean regions where the ventilation started in shallow environment and gradually 425 extended towards greater water depths towards deeper sediments-(Schmiedl et al., 2010). As the oxygen 426 reached the seabed, the authigenic enrichment of $\mathrm{MnO}_{2}$ (Fig. 10a $\underline{9}$ ) provides a geochemical redox marker 427 to track the maximum penetration of oxygen in sediments after the anoxic period (Reitz et al., 2006; 428 Tachikawa et al., 2015).

429 While OC concentration levels were re-established after the sapropel over basin and slope, the 430 OC remained relatively high in the mid-Adriatic depression (AMC99-1; Fig. 7-6 c) even after the S1 431 termination. The OI based on intermediate infaunal foraminifera reveals a relatively moderate but 432 continuous decrease of the pore-water oxygen concentration in this region throughout the S1 deposition 433 (Fig. 8 e $7 \mathrm{c}$ ). This trend likely reflected the sea level rise which pushed towards land the main path of the 434 North Adriatic Deep Water (NAdDW) causing a less efficient ventilation of the Adriatic depression. It is 435 well documented that the modern NAdDW path is mainly confined to the western shelf due to the Coriolis 436 force as it moves southwards (Vilibić and Supić, 2005). Today, only major events of dense water 437 formation can efficiently ventilate the deepest region of the Adriatic depression (Marini et al., 2015). 438 When this occurs, the dense plume lifts the old water mass which is characterized by relatively low 439 oxygen concentrations testifying its long residence time within the morphological depression (i.e., one or 440 several years) (Marini et al., 2015).

\subsection{Sediment waves growth and thermohaline forcing}

In the South Adriatic slope within the field of upslope-migrating sediment waves (core SA03-1, $444567 \mathrm{~m}$; Fig. 2c), the relative abundance of reworked inner-shelf foraminifera suddenly decreased at the S1 445 onset (Fig. 67d). The presence of allochthonous taxa at this depth is expected considering the 
446 thermohaline forcing that generates these sedimentary bodies (Trincardi et al., 2007). Specifically, 447 sediment waves are essentially swept by protracted thermohaline currents which have sufficient energy to 448 resuspend inner-shelf taxa and disperse them towards greater depths_(Langone et al., 2015). Bottom 449 currents in the southern Adriatic slope are principally controlled by LIW and NAdDW as well as their 450 interaction which ultimately generates the Adriatic Eastern Mediterranean Deep Water (EMDW $\left.{ }_{\text {Adriatic }}\right)$ 451 (Millot, 1999). Mooring lines deployed just down-flow respect to the sediment wave field showed that the 452 modern NAdDW-driven bottom currents can reach over $60 \mathrm{~cm} \mathrm{~s}^{-1}$ during the cascading season (Langone 453 et al., 2015) (i.e., the modern NAdDW forms around Jan-Feb and reaches the southern margin around 454 March-April (Langone et al., 2015; Turchetto et al., 2007). Consequently, the sudden decrease of inner455 shelf taxa coeval with the S1 onset likely reflects the virtual shutdown of the NAdDW or, more precisely, 456 a shallow ventilation confined to the uppermost region of the water column.

457 This explanation is indeed consistent with the general temporal trend shown by the shedding of 458 allochthonous foraminifera from the shelf throughout the S1 deposition. For example, as previously 459 mentioned, the S1 interruption is likely the expression of a cooling phase which promoted the temporary 460 reactivation of the dense water formation in the northern Adriatic Sea (Rohling et al., 1997) and, 461 consequently, the advection of reworked inner-shelf taxa over the slope (Fig. 7d $\underline{6 d}$ ). Likewise, S1b and S1 462 termination are associated with decrease and increase of inner-shelf taxa, respectively (Fig. 7d $\underline{6 d}$ ).

The non-cohesive fraction of marine sediments - generally known as "sortable silt" (SS, 10-63

$464 \mu \mathrm{m}$ ) - further supports the decrease of the deep-water ventilation during the S1 deposition (Fig. 7e $\underline{6 e}$ ). The 465 sortable silt is operationally defined as the fraction of fine-grained sediments whose sorting and 466 concentration vary in response to hydrodynamic processes (McCave and Hall, 2006). As large errors 467 affect the SS mean grain estimates for low concentrations of SS, here we report only the SS\% by weight 468 as a qualitative proxy for paleo-current regimes (Fig. 7e $\underline{6 e}$ ). The SS\% suggests a progressive decrease of 469 the bottom-current energy since the end of the Younger Dryas (ca. 11.5 cal ky BP) with the minimum 470 observed just at the S1 onset. Overall, the SS trend is consistent with the general distribution of the inner- 
471 shelf foraminifera (Fig. 7d $\underline{6 \mathrm{~d}}$ ), which further highlights drastic changes of the thermohaline forcing 472 associated with the pace of the NAdDW.

473

\section{$474 \quad 4.4$ Weakening of LIW as main trigger for Adriatic S1 deposits}

Our results from the sediment wave field revealed that the onset of the sapropel S1 in Adriatic sediments is coeval with the drastic weakening of the North Adriatic Deep Water (NAdDW, Fig. 1).

477 Based on this evidence, we envision a direct relation of cause and effect in which suddenly weakened 478 deep water ventilation-formation resulted in oxygen depleted bottom waters.

Several combined factors might have caused the abrupt decrease of the thermohaline forcing in 480 the Adriatic Sea. A key aspect to consider lies in the evident similarities with the south-eastern 481 Mediterranean Sea. First of all, the comparison with the Levantine, Aegean and Ionian Seas reveals that 482 the S1 onset in the Adriatic is remarkably-coeval (within age-depth model uncertainties) with the sapropel 483 formation in these regions. Specifically, a recent review (Schmiedl et al., 2010) that has compiled several south-eastern Mediterranean cores indicated that the onset of critical oxygen concentrations (i.e, oxygen index being less than 0.5 ) occurred around $10.2 \pm 0.3 \mathrm{cal}$ ky BP. The collapse of the Adriatic benthic fauna in slope and basin sediments based on the same oxygen index threshold occurred within this time interval (Fig. 810 a, b). This comparison thus reveals that S1 onset in the Adriatic was coeval with the rest of the south-eastern Mediterranean sapropel beds. Further evident similarities with the south-eastern Mediterranean sapropels-emerge when comparing the temporal anomalies of several other geochemical parameters such as bulk OC (Filippidi et al., 2016; Hennekam et al., 2014; Vigliotti et al., 2011) and redox-sensitive elements (Filippidi et al., 2016; Hennekam et al., 2014; Mercone et al., 2001; Tachikawa 492 et al., 2015) (notably vanadium). 


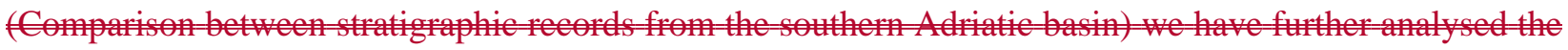

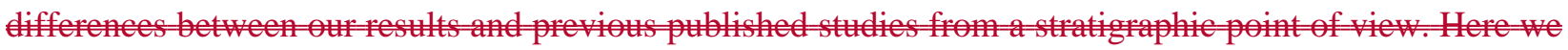
show how time differences are most likely the result of low-resolution age-depth models combined with gravity-driven processes (e.g., eresion, turbidites) which likely altered the original stratigraphy.

In light of this new new-insightinformation, we postulate that the synchronous onset of sapropel S1 over the entire EMS (Fig. 10) necessarily involves the Levantine Intermediate Water (LIW) (Fig. 12) which is the binding element of the eastern Mediterranean thermohaline circulation (Millot, 1999). More specifically, we suggest that the most plausible scenario to explain (i) the coeval S1 onset and (ii) the sudden weakening of the NAdDW must be related to the freshening of the south-eastern Mediterranean Sea. According to our hypothesis, because the salty LIW exerts first-order control on the NAdDW formation by pre-conditioning the northern Adriatic waters (Vilibić and Orlić, 2002; Vilibić and Supić, 2005) before the winter cooling, we infer that the freshening of the Levantine Sea during the African Humid Period -must have considerably reduced the deep-water formation in the northern Adriatic Sea eventually leading to the deep-water anoxia-(Fig. 12b).

To test our hypothesis (Fig. 12b) and in particular the link between the south-eastern Mediterranean region and Adriatic Sea, we have compared our data with a recent reconstruction of the Nile River discharge based on the $\mathrm{Ba} / \mathrm{Ca}$ ratio measured on Globigerinoides ruber (Weldeab et al., 2014) (Fig. $7 \mathrm{f} \underline{6 \mathrm{f}}$ ). The $\mathrm{Ba} / \mathrm{Ca}$ record essentially reflects the degree of the freshening of the Levantine surface waters as a function of the African monsoon extent (Weldeab et al., 2014). We found that the maximum freshwater supply to the Levantine Sea (ca. 10 cal ky BP) indeed corresponds to the temporarily NAdDW shutdown (i.e., drop in the inner-shelf taxa and SS, Fig. $7 \underline{6}$ d, e) and the corresponding S1 onset in the Adriatic Sea (Fig. $7 \underline{6} \underline{6} a, b, c$ and $8 \underline{7}$ a , b, c).

Furthermore, considering that the formation of the Adriatic-Eastern Mediterranean Deep Water

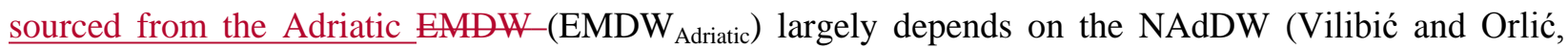
2002; Vilibić and Supić, 2005) (Fig. 1), our results imply that the reduced deep water formation in the 
Adriatic had in turn drastically hampered the ventilation of those deep regions under the direct influence of the EMDW Adriatic which today such as the Ionian basin (Fig. 12b). Today the Adriatic-represents the major cold and EMDW dense water source of for the EMS (Klein et al., 2000)-although under certain climate conditions (commonly known as the Eastern Mediterranean Transient, EMT), the south-eastern strface waters can become particularly salty and generate large volumes of dense water (Lascaratos et al., 1999; Malanotte Rizzoli et al., 1997). The EMS freshening certainly had important effects on both NAdDW and EMT.

Recent studies have also pointed out that that the progressive stagnation of the EMS occurred prior to the African Humid Period due to the inflow of less saline North Atlantic waters into the Mediterranean via the Gibraltar strait (Béthoux and Pierre, 1999; Grimm et al., 2015; Rohling and Bryden, 1994; Rohling et al., 2015). Therefore, the peak of the African monsoon occurred over a period already characterized by enhanced water-column stratification. Evidence of weakened deep-water ventilation prior to S1 has been well documented in the Levantine Basin_(Tachikawa et al., 2015) , $^{15}$, which is consistent with our record in the Adriatic basin (notably ST04-1; Fig. 9요). The presence of pre-sapropel conditions in our deepest record further highlights the coherence between the Adriatic and the rest of the EMS as well as the importance of pre-freshening as a prerequisite for the sapropel formation (Grimm et al., 2015).

Among other relevant similarities with the south-eastern Mediterranean sapropels, it is worth mentioning that the S1 termination in the Adriatic was coherent with the progressive reoxygenation observed in the Levantine and Aegean sediments_(Fig. 10). Specifically, according to the foraminiferabased oxygen index (values > 0.5) (Schmiedl et al., 2010) in these regions, the ventilation was initially confined within the uppermost water column and gradually increased water depth with time. A similar water depth- trend characterized our Adriatic records. Using the same oxygen-index threshold as for the Aegean and Levantine basins (Schmiedl et al., 2010), the re-oxygenation over the slope (SA03-1, Fig. $\$ b 7 \mathrm{~b}$ and 10) occurred much-earlier than -the deep benthic environment (ST04-1, Fig. \&a and 10). In line with the bottom--current proxies (Fig. $7 \underline{6 \mathrm{~d}}$, e), these results suggest a gradual reactivation of the 
546 NAdDW. The reason for the observed bathymetric trend across all Eastern Mediterranean basins probably 547 involves the gradual weakening of the African monsoons (Weldeab et al., 2014) (Fig. 7ffㅡ) coupled with 548 the sea surface cooling towards the end of the sapropel (Marino et al., 2009; Siani et al., 2013).

$550 \quad 4.5$ Comparison with published stratigraphic records from the southern Adriatic basin

551 Our results revealed Aa synchronous S1 onset across the entire EMS which —includes ing the

552 Adriatic setting. -This- is a new element that corrects previous literature which inferred a delayed S1 onset 553 (өf-ca. 1ky) in the Adriatic due to protracted ventilation during the early phase of the sapropel formation 554 (Rohling et al., 1997). In the 3.2In this section, we revisit published studies dealing with the Adriatic S1 to 555 evaluate the stratigraphic coherence with our results and, thus, further understand the origin of this 556 discrepancy.section (Comparison between stratigraphic records from the southern Adriatic basin) we have 557 further analysed the differences between our results and previous published studies from a stratigraphic 558 point of view. Here we show how time differences are most likely the result of low resolution age-depth 559 models combined with gravity driven processes (e.g., erosion, turbidites) which likely altered the originat 560 stratigraphy.

$561 \quad$ Prior Adriatic studies focused on the following cores: IN68-9 (Jorissen et al., 1993; Rohling et al., 562 1997; Van Straaten, 1970), MD90-197 (Mercone et al., 2001; Mercone et al., 2000; Siani et al., 2013; 563 Siani et al., 2000; Siani et al., 2010) and AD91-17 (Capotondi et al., 1999; Giunta et al., 2003; Sangiorgi 564 et al., 2003) (Fig. 1 and 11). For the comparison with our records, we selected five main widespread 565 bioevents commonly observed in the Adriatic Sea (Fig. 11) (Asioli et al., 1999; Narciso et al., 2012; Piva 566 et al., 2008; Rohling et al., 1997; Santacroce et al., 2008; Trincardi et al., 1996). Bioevents include:

567 - bioevent I (top GS-1/YD): abrupt increase of G. ruber

$568 \quad$ - bioevent II: older peak of G. inflata

569 - bioevent III: younger peak of G. inflata

$570 \quad-$ G. ruber maximum peak of frequency in S1a 
$571 \quad$ - Globoturborotalita rubescens peak in S1a

572 Among these cores, IN68-9 core (i.e., core 362 in previous publications (Van Straaten, 1970) is

573 particularly relevant because our current understanding of the S1 onset is largely based on this record

574 (Rohling et al., 1997; Rohling et al., 2015). IN68-9 was collected at $1234 \mathrm{~m}$ water depth (Fig. 11a) and all

575 the aforementioned biostratigraphic events (source PANGEA, doi:10.1594/PANGAEA.407648) are

576 present and stratigraphically coherent with ST04-1 (bioevent I corresponds in this core to the ecozones I/II

577 boundary) (Fig. 11a). Another similarity includes the ash layer at cm 128-130. Geochemical analysis in

578 IN68-9 defined this event as Mercato tephra (Calanchi and Dinelli, 2008) which is positioned just below

579 the increase of G. rubescens. Although the geochemical fingerprint is not available for ST04-1, the age

580 and the stratigraphic position suggest that this ash layer is likely Mercato tephra.

581 Despite the overall coherence between IN68-9 and ST04-1 from a stratigraphy point of view,

582 bioevents in IN68-9 exhibit a much younger age compared to ST04-1, especially within S1a. To further

583 investigate this discrepancy, we performed a new picking of planktonic foraminifera directly on IN68-9

584 close to the G. ruber peak $(137-138 \mathrm{~cm})$. It was possible to date this interval in core IN68-9 because two-

585 thirds of the original core are currently stored at ISMAR Bologna. The new radiocarbon date $(9030 \pm 30 \mathrm{yr}$

$586 \quad$ BP ${ }^{14} \mathrm{C}$ age.; NOSAMS reference OS-127850; Table 1) turned out much older than the age assessed with

587 the previous age-depth model (ca. $8110 \mathrm{yr}$ BP ${ }^{14} \mathrm{C}$ age) (Rohling et al., 1997) but remarkably consistent

$588 \quad$ with the chronology of ST04-1.

589 The reason for this offset (ca. $900 \mathrm{y}$ ) between the new radiocarbon date and the previous age-depth

590 model (Rohling et al., 1997) might explain why the Adriatic sapropel S1 exhibited a delayed onset. It is

591 worth mentioning that the age-depth model of IN68-9 within the S1 deposit, essentially relies only on two

592 radiocarbon dates (Rohling et al., 1997). Thus, it possible that the problem might derive from the lowest

593 radiocarbon date (UTC-501, 155.5-157.5 cm, 9280 $\pm 180 \mathrm{yr}$ BP ${ }^{14} \mathrm{C}$ ) which is somehow erroneously too

594 young. To test this hypothesis, we re-modelled in Oxcal the sediment accumulation of core IN68-9 using

595 the new radiocarbon date (OS-127850) and the bioevents as used in our records (supplementary material). 
596 The goal of this exercise was to examine the agreement between the model (prior) and the observational

597 data (likelihood) which is quantitatively expressed with the "agreement index". As expected, test UTC-

$598 \quad 501$ exhibited a low agreement index and, thus, turned out being an outlier. Furthermore, the agreement

599 index would further decrease considering that the suspicious radiocarbon test (UTC-501) corresponds to a

600 mixture of benthic foraminifera (Jorissen et al., 1993). In fact, if we applied a larger $\Delta \mathrm{R}$ respect to

601 planktonic foraminifera, the new reservoir correction would make the calibrated age even younger and,

602 thus, less coherent with the rest of the dates.

Core MD90-197 was collected at 1010 m water depth (Fig. 1). Three curves of planktonic species

604 (G. ruber, G. inflata and Globigerinita glutinata) were visually extrapolated based on the plot of 605 planktonic species vs age previously published (Siani et al., 2010). For this core only two bioevents of 606 core ST04-1 were recognized: Bioevent I and II. The G. ruber peak is present but it is coeval with the 607 tephra layer E1 (Gabellotto-Fiumebianco) located close to the S1 interruption and proved to be younger 608 than Mercato tephra (Caron et al., 2012; Marchini et al., 2014). What is striking about this core is the 609 relatively thin S1a compared to S1b which is unusual for S1 (Mercone et al., 2001; Mercone et al., 2000). 610 This might reflect either a condensed interval or a hiatus above the G. glutinata peak. To test this 611 hypothesis, we compared the V/Al record that displays a large peak right after the S1 onset in both 612 Adriatic basin (ST04-1) and slope (INVAS12-10) (Fig 11b). This peak is also present in other south613 eastern S1 deposits (e.g., LC21, Aegean Sea (Mercone et al., 2001). The XRF analyses were performed 614 every $\mathrm{cm}$ in MD90-197. However, despite the high resolution, the V/Al peak is not visible (Mercone et al., 615 2001) (Fig. 11b). An examination of all radiocarbon dates available for MD90-197 (both mixed planktonic 616 foraminifera and monospecific tests (Mercone et al., 2000) reveals a drastic drop in sedimentation rate 617 where the V/Al is expected. This suggests once again either a condensed unit or a hiatus. Even considering 618 the error associated with pulling together monospecific radiocarbon tests and mixed planktonic species 619 (these latter integrate the signal of a thicker water column), the apparent drop of sedimentation seems to 620 be still evident in the radiocarbon data (Mercone et al., 2000). Unfortunately, benthic foraminifera are not 
621 available for MD90-197 which hampers the direct comparison with our record. For example, the C. bradyi

622 observed in both ST04-1 and IN68-9 at the base of S1 a could have provided additional important clues.

Finally, core AD91-17 was collected in the southern Adriatic at 844 m water depth (Giunta et al.,

2003, Marchini et al., 2014). Two curves of planktonic foraminifera (G. ruber and G. inflata) were reported in Fig. 1 based on previous studies (Capotondi et al., 1999). Tephra-stratigraphy of core AD91-17 indicates that the reconstructed sapropel onset $(190-191 \mathrm{~cm})$ corresponded to the uppermost limit of Mercato tephra (Marchini et al., 2014). However, Mercato tephra is stratigraphically positioned ca. in the 628 middle of S1a, above the G. ruber peak in both IN68-9 (Calanchi and Dinelli, 2008; Rohling et al., 1997) 629 and ST04-1 (this study). The fact that this large G. ruber peak below Mercato is not visible in AD91-17 630 (Fig. 11a) suggests that the lower portion of the S1a is missing. In fact, previous publications have 631 highlighted the presence of a turbidite just below Mercato between cm 200 and 196 (Giunta et al., 2003) 632 which further support the hypothesis of a possible stratigraphic gap.

\section{4.}

Alternatively, the deposition of the Adriatic sapropel could have been an expression of the highnutrient supply via freshwater discharge. Under these circumstances, the increased demand of benthic

638 oxygen, necessary to degrade the freshly deposited marine phytodetritus, eventually resulted in anoxic 639 sediments.

In this study, we used lignin - the second most abundant macromolecule on Earth after cellulose -

641 as a tracer of freshwater discharge because it has been shown that terrestrial organic biomarkers (notably

642 sediment-normalized concentrations) increase during sapropel deposition (Bouloubassi et al., 1999;

643 Gogou et al., 2007) (Fig. 1112). In northern Mediterranean borderlands, the abundancethis evidence $\theta f$ 644 terrestrial biomarkers -has been widely used to infer the link between enhanced freshwater supply and 645 sapropel formation (Bouloubassi et al., 1999; Gogou et al., 2007). Indeed, our results show that lignin 
646 increased at the $\mathrm{S} 1$ onset but, in all settings-at the same time, the lignin content markedly diminishes with 647 decreasing water depth (Fig. 11ㄹ). While previous studies mainly drawn their conclusions based on deep 648 sapropel beds (Bouloubassi et al., 1999; Gogou et al., 2007), in this study we took the opportunity to focus 649 also on shallow water equivalent deposits which revealed this water depth trend. However, Aa pattern like 650 this is-_unexpected because typically lignin concentration diminishes with increasing distance from the 651 river outlets in all modern continental margins, including the Adriatic (Bröder et al., 2016; Gordon and 652 Goñi, 2003; Tesi et al., 2008; Tesi et al., 2007). Therefore, in our hypothesis, lignin concentration reflects 653 post-depositional degradation efficiency rather than original river input.

654 In this scenario, early diagenesis during burial is limited in the deep basin where anoxic sediments 655 hamper the complete OC breakdown including the terrestrial fraction. This would explain the relatively 656 high lignin content in the deepest station during S1 as well as the similarities between lignin content and 657 bulk OC (Fig. $7 \underline{6}$ a, b, c and 11르). Taken together, our results indicate that terrestrial biomarkers in 658 sapropel beds do not necessarily reflect a primary signal (river input) but rather a secondary signal 659 (diagenesis) as observed for other "non-conservative" variables measured in sapropel bedss such as $\delta^{15} \mathrm{~N}$, 660 pollen assemblages as well as other organic biomarkers (Cheddadi and Rossignol-Strick, 1995; Langgut et 661 al., 2011; Versteegh et al., 2010). Another recent example is the $\delta^{15} \mathrm{~N}$ whose depleted isotope composition 662 has been interpreted for a long time as a sign of enhanced primary productivity (Calvert et al., 1992). 663 Recent works showed that the lack of isotopic fractionation during early diagenesis is essentially the 664 reason why sapropel beds display depleted $\delta^{15} \mathrm{~N}$ signatures (Möbius et al., 2010; Sachs and Repeta, 1999). 665 Thus, as observed for the terrestrial biomarkers, the $\delta^{15} \mathrm{~N}$ signature in sapropel beds reflects a preservation 666 signal (diagenesis) rather than the original marine OC fingerprint.

Given the evident complications with the use of terrestrial biomarkers we have looked into the 669 literature (Combourieu-Nebout et al., 2013; Magny et al., 2012; Spötl et al., 2010) to find indications of 670 enhanced river discharge from the northern Mediterranean borderlands to justify the sapropel onset at 
671 around $10 \mathrm{cal}$ ky BP. The collective evidence based on speleothems, pollen data and debris flow fans and

672 lake levels-suggests precipitation anomalies around 7.3-8.2-7.3 cal. ky BP (Spötl et al., 2010; Zanchetta et

673 al., 2007)_over the northern Mediterranean-Italian drainage basins regions-(Alps and northern Apennine

674 chain)(i.e., Alps).(Magny et al., 2013)The wetter conditions during this period might have further

675 weakened the NADW during the sapropel deposition and stimulated the primary productivity. However,

676 other studies based on lake levels suggest conditions not particularly wet during the same period in

677 northern Italy (Magny et al., 2013). Despite the lack of agreement, (Spötl et al., 2010; Zanchetta et al.,

678 2007)it seems evident that this time interval (8.2-7.3 cal. ky BP) (Spötl et al., 2010; Zanchetta et al., 2007)

679 -is more which is more-consistent with the second phase of sapropel S1 (S1b) rather than its-the onset (ca.

$68010 \mathrm{cal} \mathrm{ky} \mathrm{BP})$. In conclusions, there is no evidence in the literature or in our river-proxy data suggesting

681 that S1 in the Adriatic was initiated by enhanced freshwater discharge from local rivers. By contrast, the

682 synchronous onset across the entire EMS suggests a wide-basin, physical-driven mechanism such as the

683 abrupt weakening of the LIW which hampered the dense water formation over the entire Eastern

$684 \quad$ Mediterranean Sea.

687 Conclusions

$688 \quad$ This study has redefined the conditions under which the Adriatic S1 formed. Our multifaceted 689 study based on integrated ecological, organic and inorganic parameters indicates that the weakening of the 690 NAdDW-Northern Adriatic Deep Water exerted first-order control on the development of anoxic bottom 691 waters in the Adriatic as well as nearby deep basins such as the Ionian Sea. The emerging picture suggests 692 a chain of events in which the intensification of monsoon precipitation over North Africa followed by the 693 weakening of the LIW-Levantine Intermediate Water ultimately suppressed the Northern Adriatic Deep 694 Water formation whichNAdDW leading to the S1 formation in the Adriatic and in those basins further 695 south under, consequently, hampered the the direct influence of the Eastern Mediterranean Deep 


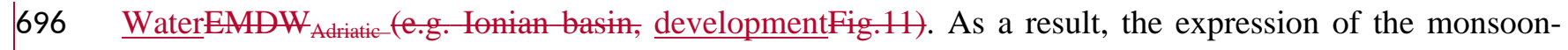

697 fuelled freshening was a synchronous stagnation \$1 formation-across the entire Eastern Mediterranean Sea

698 including the Adriatic. Finally, our results rule out the increase of nutrient supply as the major driver for

699 the S1 formation in Adriatic sediments.

700

701

702

703

704

705

706

707

708

709

710

711

712

713

714

715

716

717

718

719

720

721

722

\section{Acknowledgments}

This study was supported by Shell International Exploration and Production Inc. We thank the $R / V$ URANIA crew for at sea assistance. This is the ISMAR contribution n. XXXX. We thank Dr. L. Capotondi and Dr. L. Vigliotti for their constructive comments on the first draft of the manuscript. We also thank Dr. Daria Pasqual (University of Padova, Dept. of Geosciences) for her assistance in XRF analyses. We thank two anonymous reviewers and the Editor H. Bauch for their constructive comments. $\underline{\text { We also acknowledge Prof. Gerhard Schmiedl (Universität Hamburg) and Associate Prof. Syee Weldeab }}$ (Earth Science, UC Santa Barbara) for providing published data used in this study.

\section{References}

Ariztegui, D., Asioli, A., Lowe, J.J., Trincardi, F., Vigliotti, L., Tamburini, F., Chondrogianni, C., Accorsi, C.A., Bandini Mazzanti, M., Mercuri, A.M., Van der Kaars, S., McKenzie, J.A., Oldfield, F., 2000. Palaeoclimate and the formation of sapropel S1: inferences from Late Quaternary lacustrine and marine sequences in the central Mediterranean region. Palaeogeography, Palaeoclimatology, Palaeoecology 158, 215-240.

Asioli, A., Trincardi, F., Lowe, J., Ariztegui, D., Langone, L., Oldfield, F., 2001. Sub-millennial scale climatic oscillations in the central Adriatic during the Lateglacial: palaeoceanographic implications. Quaternary Science Reviews 20, 1201-1221. 
Asioli, A., Trincardi, F., Lowe, J., Oldfield, F., 1999. Short-term climate changes during the Last GlacialHolocene transition: comparison between Mediterranean records and the GRIP event stratigraphy. Journal of Quaternary Science 14, 373-381.

Béthoux, J.-P., Pierre, C., 1999. Mediterranean functioning and sapropel formation: respective influences of climate and hydrological changes in the Atlantic and the Mediterranean. Marine Geology 153, 29-39. Bianchi, G., Hall, I.R., McCave, I., Joseph, L., 1999. Measurement of the sortable silt current speed proxy using the Sedigraph 5100 and Coulter Multisizer Ile: Precision and accuracy. Sedimentology 46, 10011014.

Blockley, S.P., Lowe, J.J., Walker, M.J., Asioli, A., Trincardi, F., Coope, G.R., Donahue, R.E., 2004. Bayesian analysis of radiocarbon chronologies: examples from the European Late-glacial. Journal of Quaternary Science 19, 159-175.

Bouloubassi, I., Rullkötter, J., Meyers, P.A., 1999. Origin and transformation of organic matter in Pliocene-Pleistocene Mediterranean sapropels: organic geochemical evidence reviewed. Marine Geology 153, 177-197.

Bröder, L., Tesi, T., Salvadó, J.A., Semiletov, I.P., Dudarev, O.V., Gustafsson, Ö., 2016. Fate of terrigenous organic matter across the Laptev Sea from the mouth of the Lena River to the deep sea of the Arctic interior. Biogeosciences 13, 5003-5019.

Calanchi, N., Dinelli, E., 2008. Tephrostratigraphy of the last $170 \mathrm{ka}$ in sedimentary successions from the Adriatic Sea. Journal of Volcanology and Geothermal Research 177, 81-95.

Calvert, S., Nielsen, B., Fontugne, M., 1992. Evidence from nitrogen isotope ratios for enhanced productivity during formation of eastern Mediterranean sapropels.

Capotondi, L., Borsetti, A.M., Morigi, C., 1999. Foraminiferal ecozones, a high resolution proxy for the late Quaternary biochronology in the central Mediterranean Sea. Marine Geology 153, 253-274.

Caron, B., Siani, G., Sulpizio, R., Zanchetta, G., Paterne, M., Santacroce, R., Tema, E., Zanella, E., 2012. Late Pleistocene to Holocene tephrostratigraphic record from the Northern Ionian Sea. Marine Geology 311, 41-51.

Cheddadi, R., Rossignol-Strick, M., 1995. Improved preservation of organic matter and pollen in eastern Mediterranean sapropels. Paleoceanography 10, 301-309.

Combourieu-Nebout, N., Peyron, O., Bout-Roumazeilles, V., Goring, S., Dormoy, I., Joannin, S., Sadori, L., Siani, G., Magny, M., 2013. Holocene vegetation and climate changes in the central Mediterranean inferred from a high-resolution marine pollen record (Adriatic Sea). Climate of the Past 9, 2023-2042.

De Lange, G.J., Thomson, J., Reitz, A., Slomp, C.P., Principato, M.S., Erba, E., Corselli, C., 2008. Synchronous basin-wide formation and redox-controlled preservation of a Mediterranean sapropel. Nature Geoscience 1, 606-610.

Favaretto, S., Asioli, A., Miola, A., Piva, A., 2008. Preboreal climatic oscillations recorded by pollen and foraminifera in the southern Adriatic Sea. Quaternary International 190, 89-102.

Filippidi, A., Triantaphyllou, M.V., De Lange, G.J., 2016. Eastern-Mediterranean ventilation variability during sapropel S1 formation, evaluated at two sites influenced by deep-water formation from Adriatic and Aegean Seas. Quaternary Science Reviews 144, 95-106.

Giunta, S., Negri, A., Morigi, C., Capotondi, L., Combourieu-Nebout, N., Emeis, K., Sangiorgi, F., Vigliotti, L., 2003. Coccolithophorid ecostratigraphy and multi-proxy paleoceanographic reconstruction in the Southern Adriatic Sea during the last deglacial time (Core AD91-17). Palaeogeography, Palaeoclimatology, Palaeoecology 190, 39-59.

Gogou, A., Bouloubassi, I., Lykousis, V., Arnaboldi, M., Gaitani, P., Meyers, P.A., 2007. Organic geochemical evidence of Late Glacial-Holocene climate instability in the North Aegean Sea. Palaeogeography, Palaeoclimatology, Palaeoecology 256, 1-20. 
Gordon, E.S., Goñi, M.A., 2003. Sources and distribution of terrigenous organic matter delivered by the Atchafalaya River to sediments in the northern Gulf of Mexico. Geochimica et Cosmochimica Acta 67, 2359-2375.

Grimm, R., Maier-Reimer, E., Mikolajewicz, U., Schmiedl, G., Müller-Navarra, K., Adloff, F., Grant, K.M., Ziegler, M., Lourens, L.J., Emeis, K.-C., 2015. Late glacial initiation of Holocene eastern Mediterranean sapropel formation. Nature communications 6.

Hennekam, R., Jilbert, T., Schnetger, B., Lange, G.J., 2014. Solar forcing of Nile discharge and sapropel S1 formation in the early to middle Holocene eastern Mediterranean. Paleoceanography 29, 343-356.

Hilgen, F., 1991. Astronomical calibration of Gauss to Matuyama sapropels in the Mediterranean and implication for the geomagnetic polarity time scale. Earth and planetary science letters 104, 226-244.

Jorissen, F.J., 1988. Benthic foraminifera from the Adriatic Sea: principles of phenotypic variation. Utrecht Micropaleontological Bulletins 37.

Jorissen, F.J., 1999. Benthic foraminiferal successions across Late Quaternary Mediterranean sapropels. Marine Geology 153, 91-101.

Jorissen, F.J., Asioli, A., Borsetti, A., Capotondi, L., De Visser, J., Hilgen, F., Rohling, E., Van der Borg, K., Grazzini, C.V., Zachariasse, W., 1993. Late quaternary central Mediterranean biochronology. Marine Micropaleontology 21, 169-189.

Klein, B., Roether, W., Civitarese, G., Gacic, M., Manca, B.B., d'Alcala, M.R., 2000. Is the Adriatic returning to dominate the production of Eastern Mediterranean Deep Water. Geophys. Res. Lett 27, 3377-3380.

Kotthoff, U., Pross, J., Müller, U.C., Peyron, O., Schmiedl, G., Schulz, H., Bordon, A., 2008. Climate dynamics in the borderlands of the Aegean Sea during formation of sapropel S1 deduced from a marine pollen record. Quaternary Science Reviews 27, 832-845.

Langgut, D., Almogi-Labin, A., Bar-Matthews, M., Weinstein-Evron, M., 2011. Vegetation and climate changes in the South Eastern Mediterranean during the Last Glacial-Interglacial cycle (86 ka): new marine pollen record. Quaternary Science Reviews 30, 3960-3972.

Langone, L., Conese, I., Miserocchi, S., Boldrin, A., Bonaldo, D., Carniel, S., Chiggiato, J., Turchetto, M., Borghini, M., Tesi, T., 2015. Dynamics of particles along the western margin of the Southern Adriatic: Processes involved in transferring particulate matter to the deep basin. Marine Geology.

Lowe, J.J., Blockley, S., Trincardi, F., Asioli, A., Cattaneo, A., Matthews, I.P., Pollard, M., Wulf, S., 2007. Age modelling of late Quaternary marine sequences in the Adriatic: Towards improved precision and accuracy using volcanic event stratigraphy. Continental Shelf Research 27, 560-582.

Magny, M., Combourieu-Nebout, N., De Beaulieu, J., Bout-Roumazeilles, V., Colombaroli, D., Desprat, S., Francke, A., Joannin, S., Peyron, O., Revel, M., 2013. North-south palaeohydrological contrasts in the central Mediterranean during the Holocene: tentative synthesis and working hypotheses. Climate of the Past Discussions 9, 1901-1967 (IF 1903,1509).

Magny, M., Joannin, S., Galop, D., Vannière, B., Haas, J.N., Bassetti, M., Bellintani, P., Scandolari, R., Desmet, M., 2012. Holocene palaeohydrological changes in the northern Mediterranean borderlands as reflected by the lake-level record of Lake Ledro, northeastern Italy. Quaternary Research 77, 382-396.

Marchini, G., Zanchetta, G., Santacroce, R., Vigliotti, L., Capotondi, L., Sulpizio, R., 2014. Tephrostratigraphy of marine core AD91-17 (Adriatic Sea) Revised. Alpine and Mediterranean Quaternary 27, 77-84.

Marini, M., Maselli, V., Campanelli, A., Foglini, F., Grilli, F., 2015. Role of the Mid-Adriatic deep in dense water interception and modification. Marine Geology.

Marino, G., Rohling, E.J., Sangiorgi, F., Hayes, A., Casford, J.L., Lotter, A.F., Kucera, M., Brinkhuis, H., 2009. Early and middle Holocene in the Aegean Sea: interplay between high and low latitude climate variability. Quaternary Science Reviews 28, 3246-3262.

McCave, I., Hall, I.R., 2006. Size sorting in marine muds: Processes, pitfalls, and prospects for paleoflow-speed proxies. Geochemistry, Geophysics, Geosystems 7. 
Mercone, D., Thomson, J., Abu-Zied, R., Croudace, I., Rohling, E., 2001. High-resolution geochemical and micropalaeontological profiling of the most recent eastern Mediterranean sapropel. Marine Geology 177, 25-44.

Mercone, D., Thomson, J., Croudace, I., Siani, G., Paterne, M., Troelstra, S., 2000. Duration of S1, the 821 most recent sapropel in the eastern Mediterranean Sea, as indicated by accelerator mass spectrometry

\section{radiocarbon and geochemical evidence. Paleoceanography 15, 336-347.}

Millot, C., 1999. Circulation in the western Mediterranean Sea. Journal of Marine Systems 20, 423-442.

Minisini, D., Trincardi, F., Asioli, A., 2006. Evidence of slope instability in the Southwestern Adriatic Margin. Natural Hazards and Earth System Science 6, 1-20.

Möbius, J., Lahajnar, N., Emeis, K.-C., 2010. Diagenetic control of nitrogen isotope ratios in Holocene sapropels and recent sediments from the Eastern Mediterranean Sea. Biogeosciences 7, 3901-3914.

Narciso, Á., Flores, J.-A., Cachão, M., Piva, A., Asioli, A., Andersen, N., Schneider, R., 2012. Late GlacialHolocene transition in the southern Adriatic Sea: Coccolithophore and Foraminiferal evidence. micropaleontology, 523-538.

Nieuwenhuize, J., Maas, Y.E.M., Middelburg, J.J., 1994. Rapid analysis of organic carbon and nitrogen in particulate materials. Marine Chemistry 45, 217-224.

Nijenhuis, I., Schenau, S., Van der Weijden, C., Hilgen, F., Lourens, L., Zachariasse, W., 1996. On the origin of upper Miocene sapropelites: a case study from the Faneromeni section, Crete (Greece). Paleoceanography 11, 633-645.

Passier, H.F., Middelburg, J.J., de Lange, G.J., Böttcher, M.E., 1997. Pyrite contents, microtextures, and sulfur isotopes in relation to formation of the youngest eastern Mediterranean sapropel. Geology 25, 519-522.

Piva, A., 2007. Stratigrafia ad alta risoluzione dei depositi Quaternari in Adriatico centrale e meridionale:impatto di cambiamenti climatici a scala sub-Milankoviana sulla circolazione in Mediterraneo, University of Bologna. Bologna, Bologna.

Piva, A., Asioli, A., Trincardi, F., Schneider, R.R., Vigliotti, L., 2008. Late-Holocene climate variability in the Adriatic sea (Central Mediterranean). The Holocene 18, 153-167.

Ramsey, C.B., 1995. Radiocarbon calibration and analysis of stratigraphy; the OxCal program. Radiocarbon 37, 425-430.

Ramsey, C.B., Lee, S., 2013. Recent and planned developments of the program OxCal. Radiocarbon 55, 720-730.

Reimer, P.J., Bard, E., Bayliss, A., Beck, J.W., Blackwell, P.G., Bronk Ramsey, C., Buck, C.E., Cheng, H., Edwards, R.L., Friedrich, M., 2013. IntCal13 and Marine13 radiocarbon age calibration curves 0-50,000 years cal BP.

Reitz, A., Thomson, J., de Lange, G.J., Hensen, C., 2006. Source and development of large manganese enrichments above eastern Mediterranean sapropel S1. Paleoceanography 21.

Rogerson, M., Cacho, I., Jimenez-Espejo, F., Reguera, M.I., Sierro, F.J., Martinez-Ruiz, F., Frigola, J., Canals, M., 2008. A dynamic explanation for the origin of the western Mediterranean organic-rich layers. Geochemistry, Geophysics, Geosystems 9, n/a-n/a.

Rohling, E., Bryden, H., 1994. Estimating past changes in the Eastern Mediterranean freshwater budget, using reconstructions of sea level and hydrography. Proceedings of the Koninklijke Nederlandse Akademie van Wetenschappen 97, 201-217.

Rohling, E., Jorissen, F., De Stigter, H., 1997. 200 year interruption of Holocene sapropel formation in the Adriatic Sea. Journal of Micropalaeontology 16, 97-108.

Rohling, E., Marino, G., Grant, K., 2015. Mediterranean climate and oceanography, and the periodic development of anoxic events (sapropels). Earth-Science Reviews 143, 62-97.

Rossignol-Strick, M., 1985. Mediterranean Quaternary sapropels, an immediate response of the African monsoon to variation of insolation. Palaeogeography, palaeoclimatology, palaeoecology 49, 237-263. 
Rossignol-Strick, M., Nesteroff, W., Olive, P., Vergnaud-Grazzini, C., 1982. After the deluge: Mediterranean stagnation and sapropel formation.

867 Sachs, J.P., Repeta, D.J., 1999. Oligotrophy and nitrogen fixation during eastern Mediterranean sapropel 868 events. Science 286, 2485-2488.

869 Sangiorgi, F., Capotondi, L., Combourieu Nebout, N., Vigliotti, L., Brinkhuis, H., Giunta, S., Lotter, A.F., 870 Morigi, C., Negri, A., Reichart, G.J., 2003. Holocene seasonal sea-surface temperature variations in the southern Adriatic Sea inferred from a multiproxy approach. Journal of Quaternary Science 18, 723-732. Santacroce, R., Cioni, R., Marianelli, P., Sbrana, A., Sulpizio, R., Zanchetta, G., Donahue, D.J., Joron, J.L., 2008. Age and whole rock-glass compositions of proximal pyroclastics from the major explosive eruptions of Somma-Vesuvius: a review as a tool for distal tephrostratigraphy. Journal of Volcanology and Geothermal Research 177, 1-18.

Santvoort, P., Lange, G., Langereis, C., Dekkers, M., Paterne, M., 1997. Geochemical and paleomagnetic evidence for the occurrence of "missing" sapropels in eastern Mediterranean sediments. Paleoceanography 12, 773-786.

Schmiedl, G., Kuhnt, T., Ehrmann, W., Emeis, K.-C., Hamann, Y., Kotthoff, U., Dulski, P., Pross, J., 2010. Climatic forcing of eastern Mediterranean deep-water formation and benthic ecosystems during the past 22000 years. Quaternary Science Reviews 29, 3006-3020.

Schmiedl, G., Mitschele, A., Beck, S., Emeis, K.-C., Hemleben, C., Schulz, H., Sperling, M., Weldeab, S., 2003. Benthic foraminiferal record of ecosystem variability in the eastern Mediterranean Sea during times of sapropel S 5 and S 6 deposition. Palaeogeography, Palaeoclimatology, Palaeoecology 190, 139164.

Siani, G., Magny, M., Paterne, M., Debret, M., Fontugne, M., 2013. Paleohydrology reconstruction and Holocene climate variability in the South Adriatic Sea. Climate of the Past 9, 499-515.

Siani, G., Paterne, M., Arnold, M., Bard, E., Métivier, B., Tisnerat, N., Bassinot, F., 2000. Radiocarbon reservoir ages in the Mediterranean Sea and Black Sea. Radiocarbon 42, 271-280.

Siani, G., Paterne, M., Colin, C., 2010. Late glacial to Holocene planktic foraminifera bioevents and climatic record in the South Adriatic Sea. Journal of Quaternary Science 25, 808-821.

Spagnoli, F., Dell'Anno, A., De Marco, A., Dinelli, E., Fabiano, M., Gadaleta, M.V., Ianni, C., Loiacono, F., Manini, E., Marini, M., 2010. Biogeochemistry, grain size and mineralogy of the central and southern Adriatic Sea sediments: a review. Chemistry and Ecology 26, 19-44.

Spötl, C., Nicolussi, K., Patzelt, G., Boch, R., 2010. Humid climate during deposition of sapropel 1 in the Mediterranean Sea: Assessing the influence on the Alps. Global and Planetary Change 71, 242-248.

Tachikawa, K., Vidal, L., Cornuault, M., Garcia, M., Pothin, A., Sonzogni, C., Bard, E., Menot, G., Revel, M., 2015. Eastern Mediterranean Sea circulation inferred from the conditions of S1 sapropel deposition. Clim. Past 11, 855-867.

Tesi, T., Langone, L., Goni, M., Turchetto, M., Miserocchi, S., Boldrin, A., 2008. Source and composition of organic matter in the Bari canyon (Italy): dense water cascading versus particulate export from the upper ocean. Deep Sea Research Part I: Oceanographic Research Papers 55, 813-831.

Tesi, T., Miserocchi, S., Goni, M.e.a., Langone, L., Boldrin, A., Turchetto, M., 2007. Organic matter origin and distribution in suspended particulate materials and surficial sediments from the western Adriatic Sea (Italy). Estuarine, Coastal and Shelf Science 73, 431-446.

Tesi, T., Semiletov, I., Hugelius, G., Dudarev, O., Kuhry, P., Gustafsson, Ö., 2014. Composition and fate of terrigenous organic matter along the Arctic land-ocean continuum in East Siberia: Insights from biomarkers and carbon isotopes. Geochimica et Cosmochimica Acta 133, 235-256.

Toucanne, S., Minto'o, C.M.A., Fontanier, C., Bassetti, M.-A., Jorry, S.J., Jouet, G., 2015. Tracking rainfall in the northern Mediterranean borderlands during sapropel deposition. Quaternary Science Reviews 129, 178-195. 
Trincardi, F., Cattaneo, A., Asioli, A., Correggiari, A., Langone, L., 1996. Stratigraphy of the lateQuaternary deposits in the central Adriatic basin and the record of short-term climatic events. MEMORIE-ISTITUTO ITALIANO DI IDROBIOLOGIA 55, 39-70.

Trincardi, F., Verdicchio, G., Miserocchi, S., 2007. Seafloor evidence for the interaction between cascading and along-slope bottom water masses. Journal of Geophysical Research: Earth Surface 112. Turchetto, M., Boldrin, A., Langone, L., Miserocchi, S., Tesi, T., Foglini, F., 2007. Particle transport in the Bari canyon (southern Adriatic Sea). Marine Geology 246, 231-247.

Van Straaten, L., 1970. Holocene and late-Pleistocene sedimentation in the Adriatic Sea. Geologische Rundschau 60, 106-131.

Versteegh, G.J.M., Zonneveld, K.A.F., de Lange, G.J., 2010. Selective aerobic and anaerobic degradation of lipids and palynomorphs in the Eastern Mediterranean since the onset of sapropel S1 deposition. Marine Geology 278, 177-192.

Vigliotti, L., Asioli, A., Bergami, C., Capotondi, L., Piva, A., 2011. Magnetic properties of the youngest sapropel S1 in the Ionian and Adriatic Sea: inference for the timing and mechanism of sapropel formation. Italian journal of geosciences 130, 106-118.

Vigliotti, L., Verosub, K., Cattaneo, A., Trincardi, F., Asioli, A., Piva, A., 2008. Palaeomagnetic and rock magnetic analysis of Holocene deposits from the Adriatic Sea: detecting and dating short-term fluctuations in sediment supply. The Holocene 18, 141-152.

Vilibić, I., Orlić, M., 2002. Adriatic water masses, their rates of formation and transport through the Otranto Strait. Deep Sea Research Part I: Oceanographic Research Papers 49, 1321-1340.

Vilibić, I., Supić, N., 2005. Dense water generation on a shelf: the case of the Adriatic Sea. Ocean Dynamics 55, 403-415.

Weldeab, S., Menke, V., Schmiedl, G., 2014. The pace of East African monsoon evolution during the Holocene. Geophysical Research Letters 41, 1724-1732.

Zanchetta, G., Drysdale, R.N., Hellstrom, J.C., Fallick, A.E., Isola, I., Gagan, M.K., Pareschi, M.T., 2007. Enhanced rainfall in the Western Mediterranean during deposition of sapropel S1: stalagmite evidence from Corchia cave (Central Italy). Quaternary Science Reviews 26, 279-286. 


\section{Captions}

951

956 Figure 1. Map of the study area in the Adriatic Sea. Coring sites are displayed as filled dots and labelled 957 AMC99-1 (260 m water depth), SA03-1 (567 m water depth), INVAS12-10 (570 m water depth) and 958 ST04-1 (1085 m water depth) respectively. Arrows show the main water masses which include the 959 Levantine Intermediate Water (LIW, red, main path, and dashed red, northward intrusion with large inter960 decadal variability), North and South-Adriatic Deep Water (NAdDW-and SAdDW, blue) and the Eastern 961 Mediterranean Deep Water (EMDW, green). Dashed line roughly displays the position of the shoreline at 962 the S1 onset. The black line represents the location of the depth profile (Fig. 2a). The upper right inset 963 shows the main path of the LIW in the eastern and central Mediterranean Sea and the Nile runoff input 
979 Figure 2. Chirp profiles of the coring sites along the shelf-basin continuum. (a) The depth profile graph 980 displays the general location of the sediment cores in respect to the dominant water masses (NAdDW and 981 LIW). Seismic profiles through the three coring sites: (b) shelf-adjacent (mid-Adriatic depression, 982 AMC99-1), (c) slope (sediment wave field, SA03-1 and INVAS12-10) and (d) deep basin (ST04-1). 
987

988

989

990

991

992

993

994

995

996

997

998

999

1000

1001

1002

1003

1004

1005

1006

1007

1008 
1009 Figure 3. Sediment cores from the Adriatic Sea (Fig. 1 and 2). Lithology, photo, false colours and XRAY 1010 of AMC99-1 (a), photo non available); INVAS12-10 (b); and ST04-1 (c). 
1031 Figure 4. Down-core biostratigraphy of ST04-1, SA03-1 and AMC99-1. Four bioevents were used for the 1032 age-depth model: I (top YD, blue line), II (older peak G. inflata, light green), III (younger peak G. inflata, 1033 dark green), IV (last occurrence G. inflata, red line). For further details on the bioevents see Table 1 and 1034 method section. The figure shows also the correlation between twins core Core SA03-1 and INVAS12-10. 1035 collected in the sediment wave field. Cross-correlation between twin cores relays on bioevents and tephra 1036 (magnetic susceptibility anomalies). Events in chronological order include: top of the Younger Dryas, two 1037 Globorotalia inflata peaks (during the Pre Boreal), peak of Cassidulinoides bradyi, a large magnetic 1038 susceptibility peak marking a tephra layer, two G. inflata peaks (during S1 break and S1b, respectively) 1039 and the last Occurrence of G. inflata

1040

1041

1042

1043

1044

1045 
1061 Figure 5. Bayesian age-depth model of Adriatic records (median, $1 \sigma$ and $2 \sigma$ ). Filled symbols (circles, 1062 squares and diamonds) show the radiocarbon dates used for the Bayesian model. Dark gray areas display 1063 distinct bioevents used to increase the model resolution and synchronize the records. The model shows 1064 good agreement between bioevents and the new radiocarbon dates of monospecific tests. For further 1065 details about the age-depth model see the method section. The paleoceanographic (and stratigraphic) 1066 events were identified independently in each core; therefore, all dates in each core are consistent and 1067 independent as no age is exported from one core to another. 
1085 Figtre 6. Comparisen between sediment cores collected in the southern Adriatie basin. ST04-1) (this 1086 study), IN68-9 (Rohling et al., 1997), MD90-197 (Mereone et al., 2001; Siani et al., 2010) and AD90-17

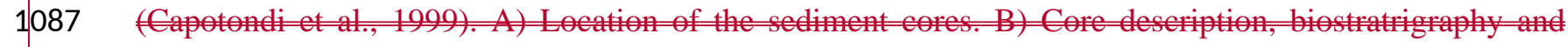




2

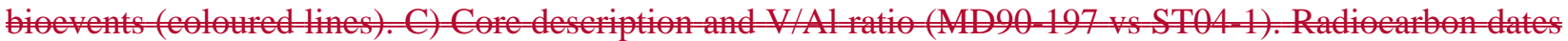

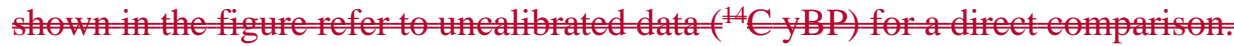

.

.


108 silt (e) over the slope (SA03-1). (f) Nile runoff proxy: Ba/Ca of Globigerinoides ruber_(Weldeab et al., 1109 2014). Light and dark grey areas denote pre-sapropel sediments, the-S1 boundaries and the sapropel S1 1110 break based on the OC content of ST04-1.

1129 Figure 87. Seafloor oxygen content and reducing conditions during the sapropel S1 deposition in Adriatic 1130 sediment along the shelf-basin continuum. Foraminifera-based oxygen index (OI, (Schmiedl et al., 2010) 
1131 of (a) ST04-1, (b) SA03-01 and AMC99-1). Value of 1 refers to fully oxygenated conditions while 0 1132 represents azoic environment, respectively. Note, OI of AMC99-1 is based on intermediate infaunal 1133 foraminifera. Authigenic vanadium enrichment (V/Ti) of (ad) ST04-1, (be $)$ SA03-01 and (f) AMC99-1. 1134 Light and dark grey areas show pre-sapropel sediments, the-S1 boundaries and interruption based on the 1135 OC content of ST04-1 (see Fig. 1ㅁ). 
1154 Figure 9․ Pre-sapropel and sapropel S1 onset in the Adriatic basin (ST04-1, $1085 \mathrm{~m})$. (a) Organic carbon 1155 (OC) and oxygen index. (b) Abundance of deep and intermediate infaunal foraminifera and authigenic 1156 vanadium enrichment $\left(\mathrm{V} / \mathrm{TiO}_{2}\right)$. Light grey area shows the azoic environment. 
1179 1180 1181

Figure 109. Distribution of manganese and sulfur during the $\mathrm{S} 1$ deposition in Adriatic sediments along the shelf-basin continuum. Authigenic manganese enrichment of (a) ST04-1, (b) INVAS12-10 and (c) AMC99-1. Authigenic sulfur enrichment of (d) ST04-1, (e) INVAS12-10 and (f) AMC99-1. Light and dark grey areas show pre-sapropel sediments, S1 boundaries and interruption based on the OC content of ST04-1 (see Fig. 6). . Light and dark grey areas show the S1 boundaries and interruption based on the OC content (see Fig. 1). Note the different scale of y-axes.

Figure 10. Benthic ecosystem changes over water depth during the sapropel S1 deposition according to the foraminifera-based oxygen index. Changes were defined using the oxygen index threshold according to Schmiedl et al. (2010). Values less than 0.5 indicate the collapse of the benthic ecosystem while values more than 0.5 indicate the recovery of the benthic ecosystem. Solid line and grey area show mean and $\underline{\text { standard deviation of the S1 onset, respectively. Dashed line (interpolation water depth vs time) exhibits }}$ the progressive ventilation with increasing water depth over time. Aegean and Levantine data from Schmiedl et al. (2010).

Figure 611. Comparison between sediment cores collected in the southern Adriatic basin. ST04-1 (this study), IN68-9 (Rohling et al., 1997), MD90-197 (Mercone et al., 2001; Siani et al., 2010) and AD90-17 (Capotondi et al., 1999). A) Location of the sediment cores. B) Core description, biostratrigraphy and bioevents (coloured lines). C) Core description and V/Al ratio (MD90-197 vs ST04-1). Radiocarbon dates shown in the figure refer to uncalibrated data $\left({ }^{14} \mathrm{C}\right.$ yBP $)$ for a direct comparison. 
1216 Figure 121. Terrigenous organic carbon concentration during the sapropel S1 deposition in Adriatic sediments along the shelf-basin continuum. Lignin concentration of (a) ST04-1, (b) INVAS12-10 and (c)

1218 AMC99-1. Light and dark grey areas show the S1 boundaries and interruption based on the OC content 1219 (see Fig. 1). Light and dark grey areas show pre-sapropel sediments, S1 boundaries and interruption based 1220 on the OC content of ST04-1 (see Fig. 6).- Note the different scale of y-axes. 


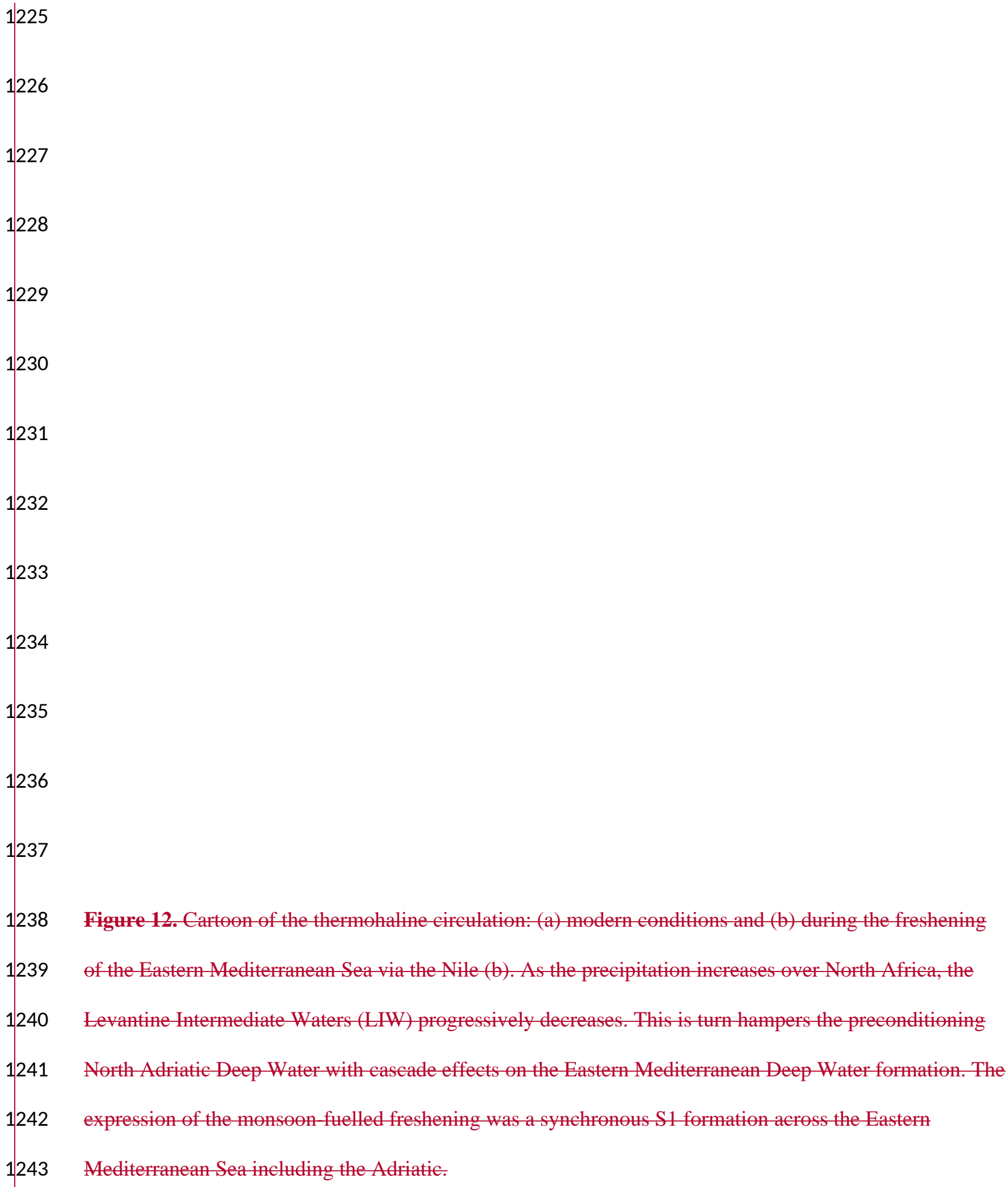

Table S1. Dated levels used for the Bayesian age-depth model of core AMC991, INVAS12-10, ST04-1. The table contains a new radiocarbon date of core IN68-9 as well. 


\begin{tabular}{|c|c|c|c|c|c|c|c|}
\hline & & & & Modelled & & & \\
\hline Lab. \# & $\begin{array}{c}\text { Core depth } \\
\text { (cm) }\end{array}$ & Sample type & $\begin{array}{c}{ }^{14} \mathrm{C} \text { age } \\
(\mathrm{yBP})\end{array}$ & $\begin{array}{c}\text { age } \\
\text { (median, } \\
\text { cal yBP) }\end{array}$ & $-2 \delta$ & $+2 \delta$ & Reference \\
\hline
\end{tabular}

\section{AMC99-1 (260 m w.d.)}

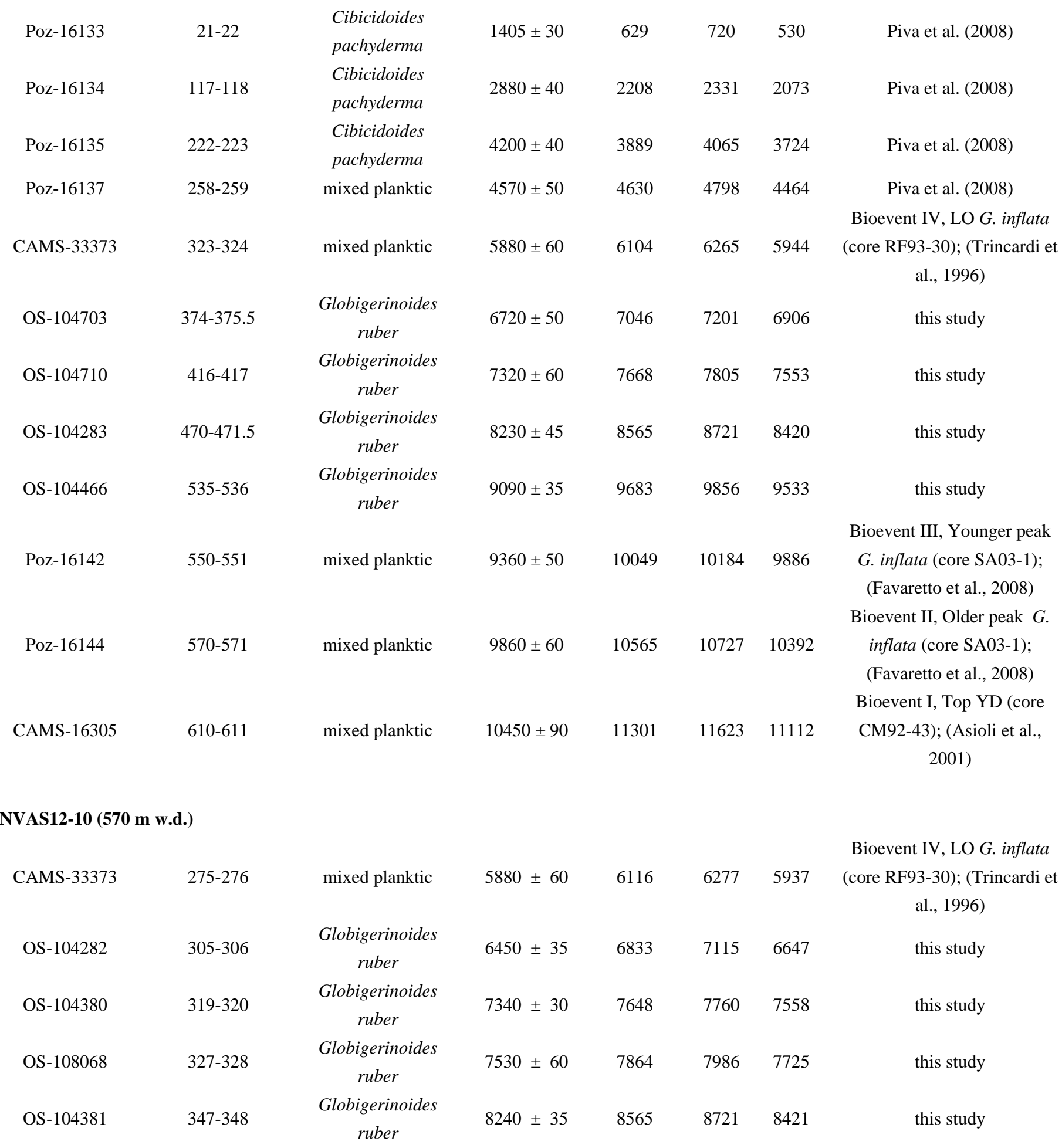




\begin{tabular}{|c|c|c|c|c|c|c|c|}
\hline OS-104382 & $375-376$ & $\begin{array}{c}\text { Globigerinoides } \\
\text { ruber }\end{array}$ & $9140 \pm 35$ & 9596 & 9982 & 9151 & this study \\
\hline Poz-16142 & $389-390$ & mixed planktic & $9360 \pm 50$ & 10100 & 10232 & 9885 & $\begin{array}{l}\text { Bioevent III, Younger peak } \\
\text { G. inflata (core SA03-1); } \\
\text { (Favaretto et al., 2008) }\end{array}$ \\
\hline Poz-16144 & $395-396$ & mixed planktic & $9860 \pm 60$ & 10577 & 10768 & 10373 & $\begin{array}{l}\text { Bioevent II, Older peak } G \text {. } \\
\text { inflata (core SA03-1); } \\
\text { (Favaretto et al., 2008) }\end{array}$ \\
\hline CAMS-16305 & $413-414$ & mixed planktic & $10450 \pm 90$ & 11301 & 11682 & 11088 & $\begin{array}{c}\text { Bioevent I, Top YD (core } \\
\text { CM92-43); (Asioli et al., } \\
\text { 2001) }\end{array}$ \\
\hline
\end{tabular}

\section{ST04-1 (1085 m w.d.)}

CAMS-33373

80-81

mixed planktic

$5880 \pm 60$

6103

$6275 \quad 5925$

Bioevent IV, LO G. inflata

OS-104464

102-103

Globigerinoides

$$
\text { ruber }
$$

$6510 \pm 30$

6878

$7011 \quad 6735$

(core RF93-30); (Trincardi et

OS-104378

113-114

OS-104465

$120-121$

Globigerinoides

ruber

Globigerinoides

ruber

OS-104281

139-140

OS-107637

$142-143$ ruber
Globigerinoides
ruber

Globigerinoides

$7160 \pm 30$

7521

$7800 \pm 35$

8110

$8254 \quad 7985$

$9040 \pm 40$

9562

$9701 \quad 9455$

$9180 \pm 40$

9755

$9916 \quad 9580$

al., 1996)

this study

this study

this study

this study

this study

Bioevent III, Younger peak

Poz-16142

145-146

mixed planktic

$9360 \pm 50$

10009

101819826

G. inflata (core SA03-1);

(Favaretto et al., 2008)

Bioevent II, Older peak $G$.

Poz-16144

153-154

mixed planktic

$9860 \pm 60$

10669

1084210505

inflata (core SA03-1);

(Favaretto et al., 2008)

OS-104379

154-155

Globorotalia inflata

$10050 \pm 45$

10761

$10949 \quad 10624$

this study

CAMS-16305

169-170

mixed planktic

$10450 \pm 90$

11442

11790

11165

Bioevent I, Top YD (core

CM92-43); (Asioli et al., 2001)

|IN68-9 (1234 m-w.d.)

$$
\text { OS- } 127850
$$

* For further details about biostratigraphy and bioevents see the method section in the main text 


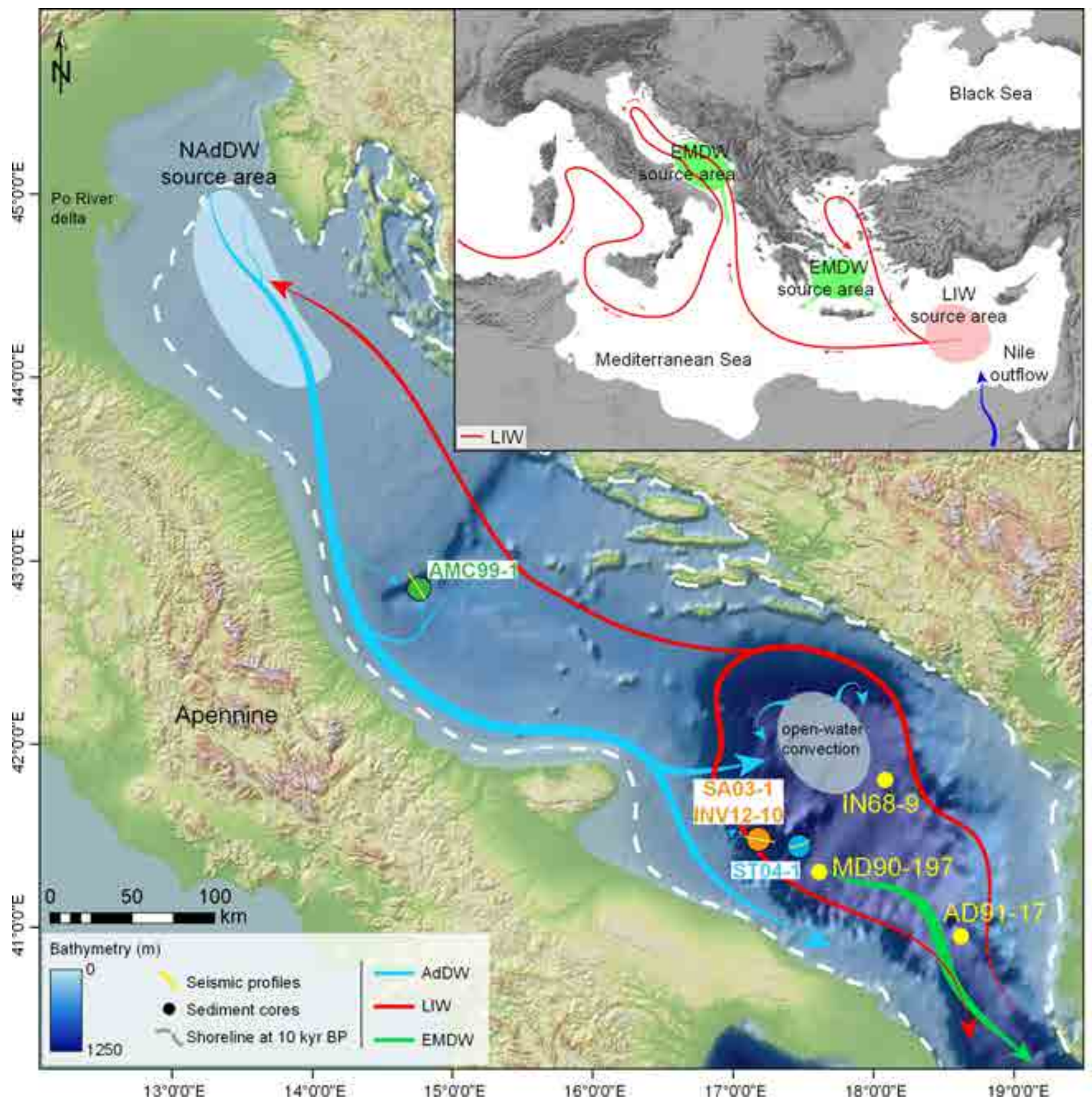




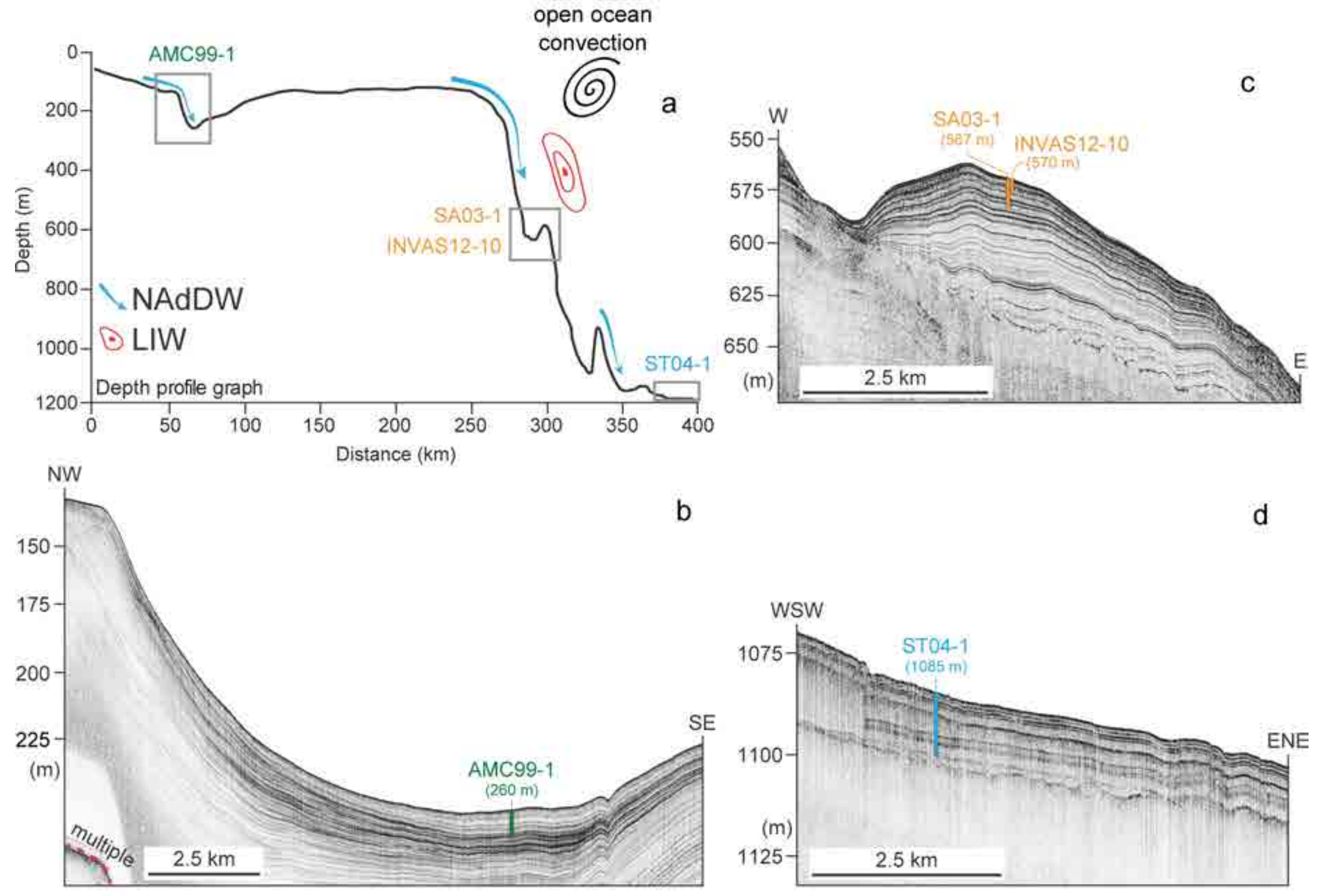


core AMC99-1 (260 m)

a

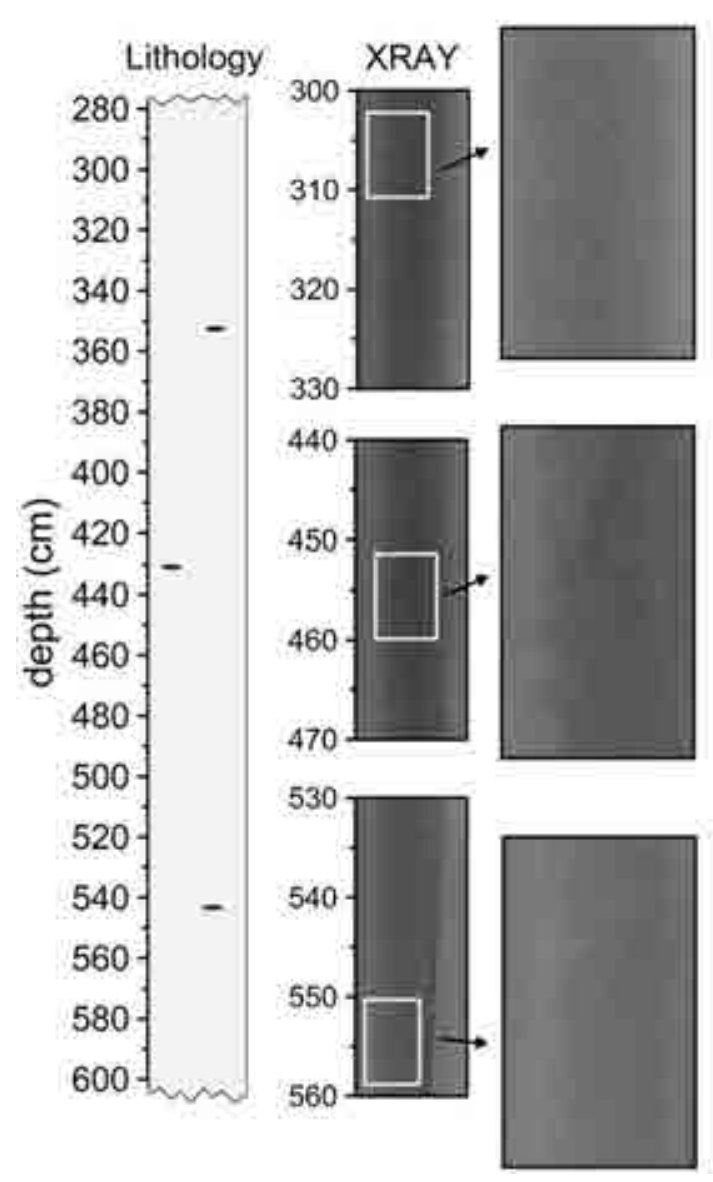

core INVAS12-10 (570 m)

Photo

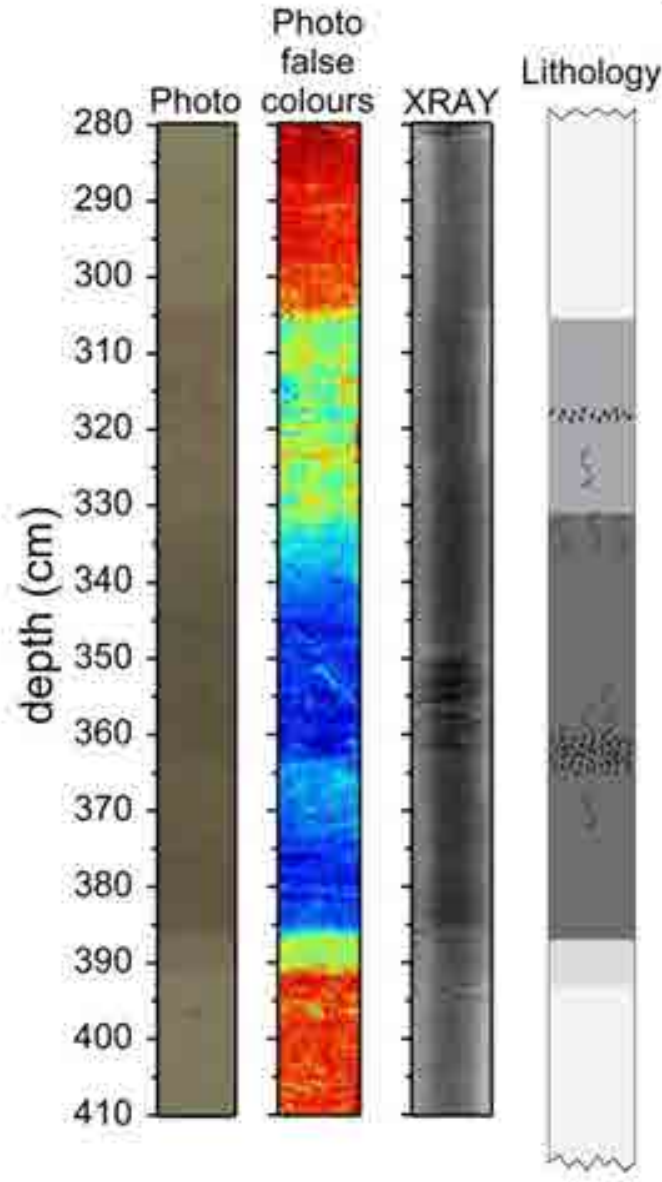

core ST04-1 (1085 m)

C

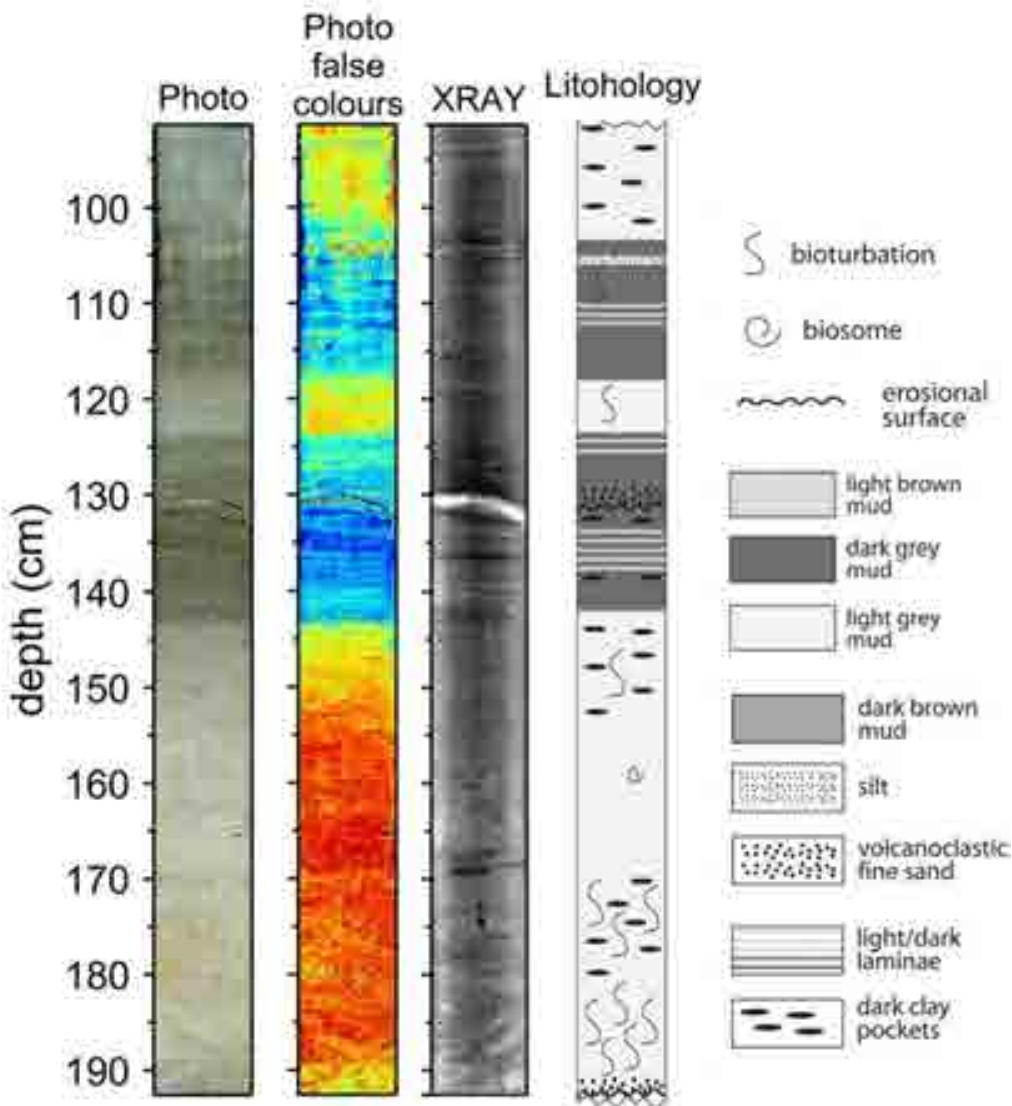




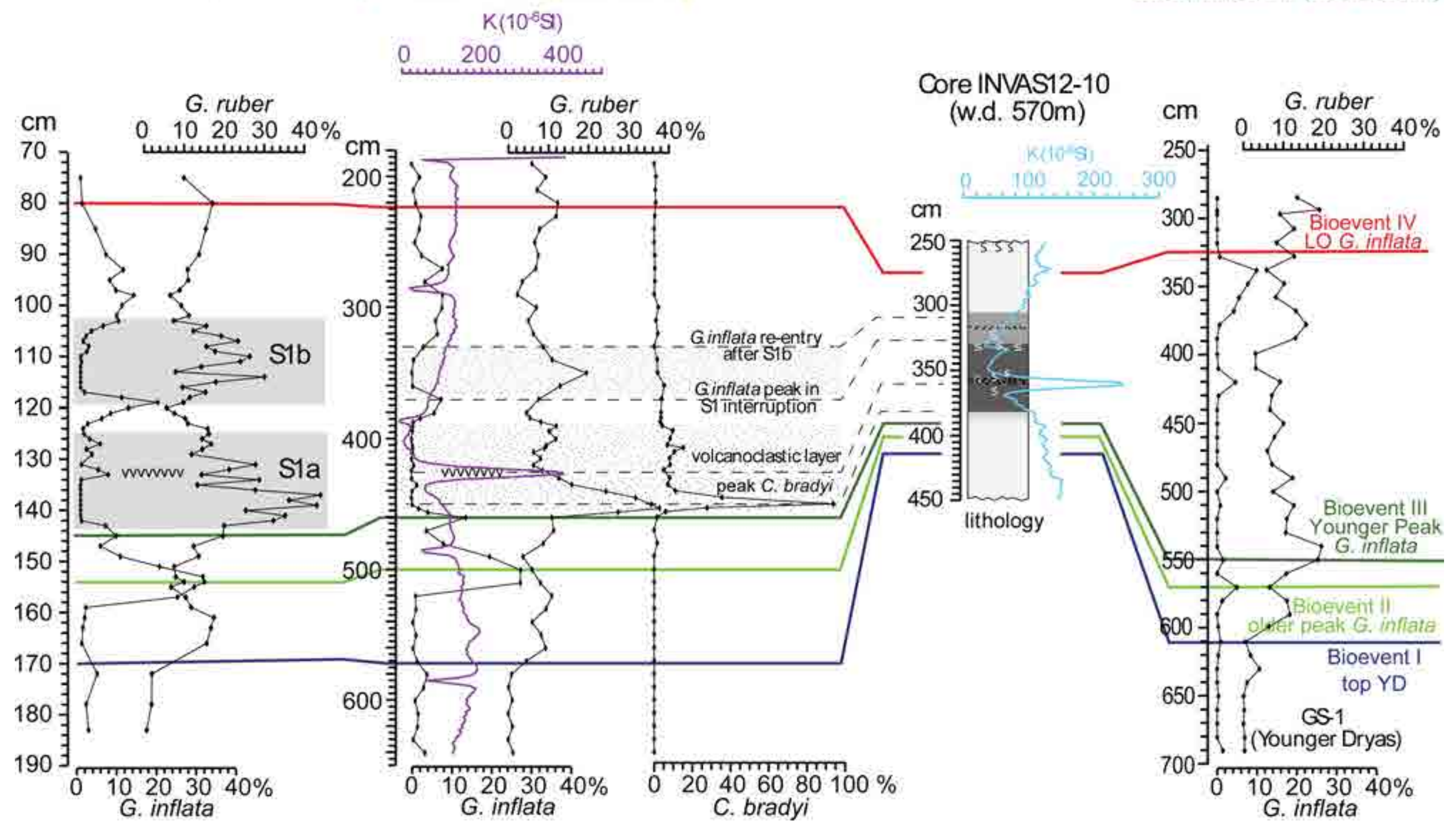




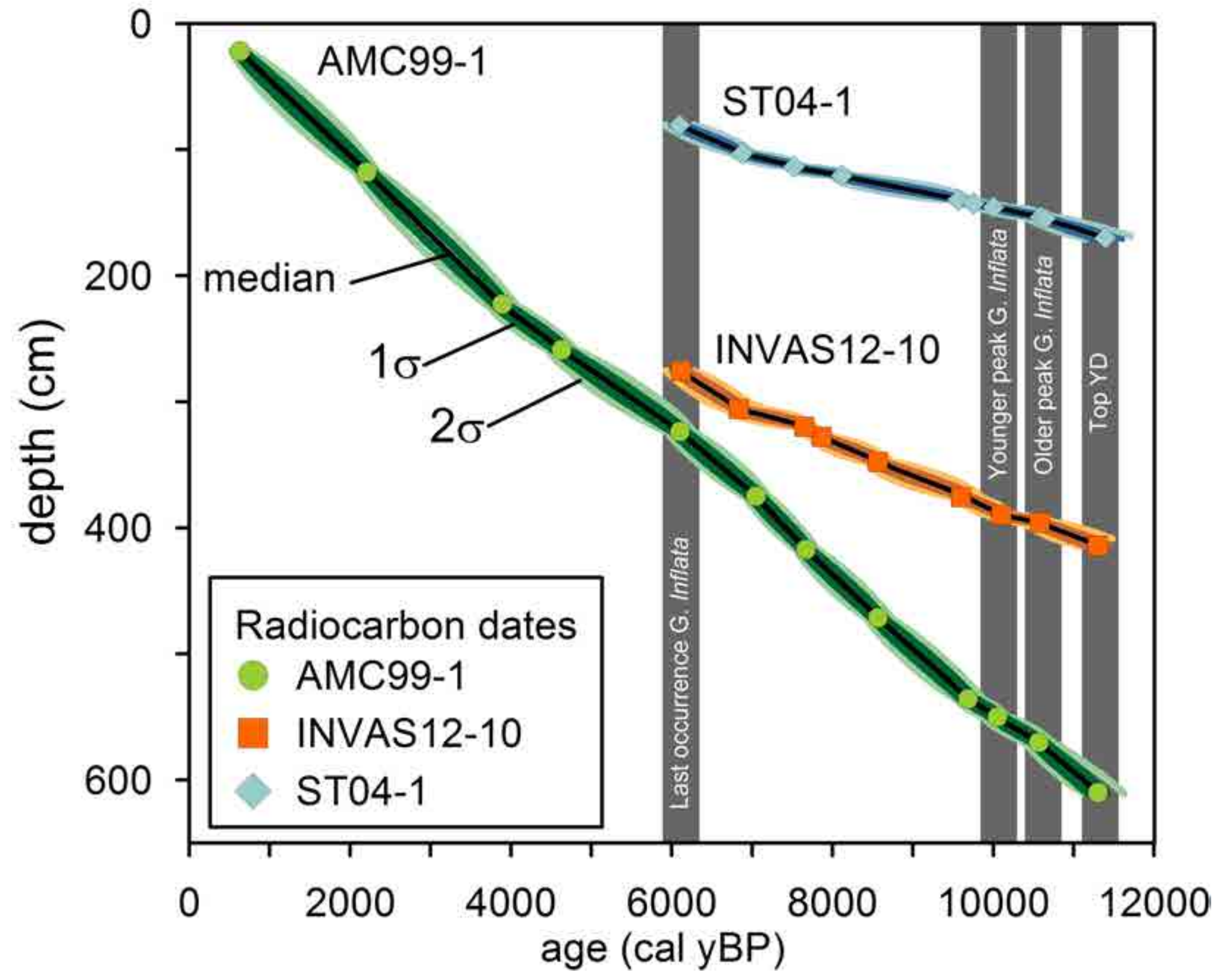




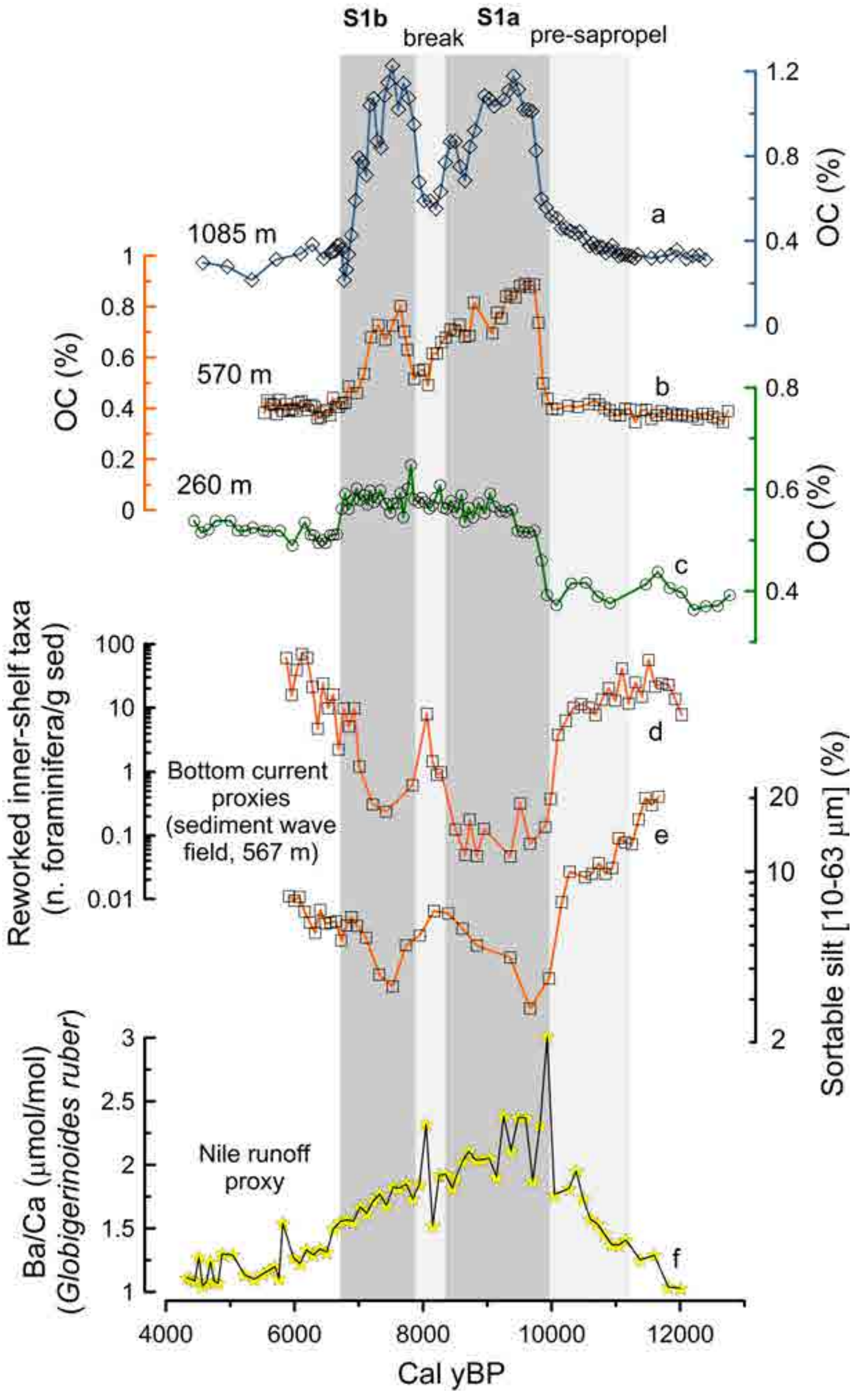




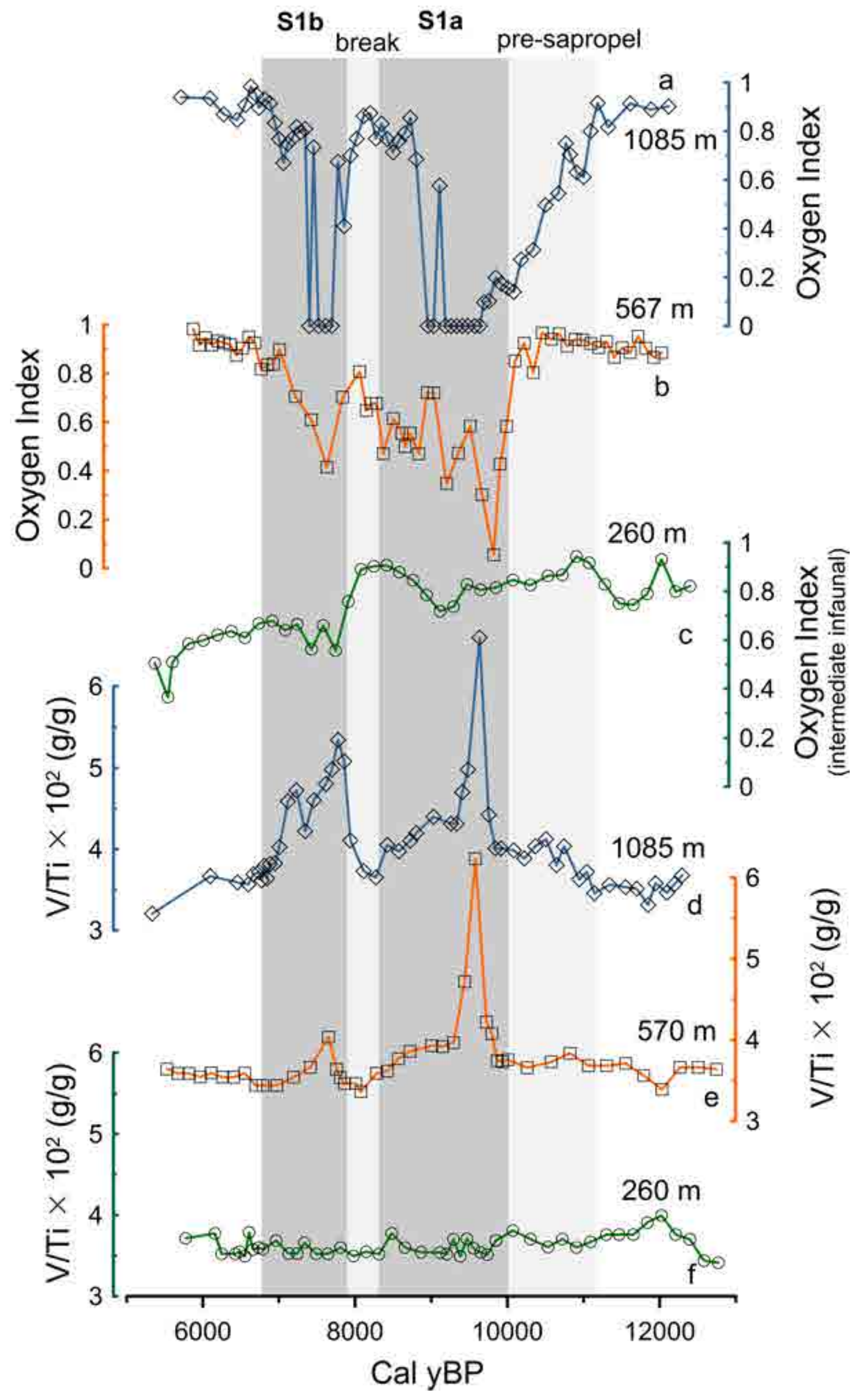




\section{core ST04-1 (1085 m)}
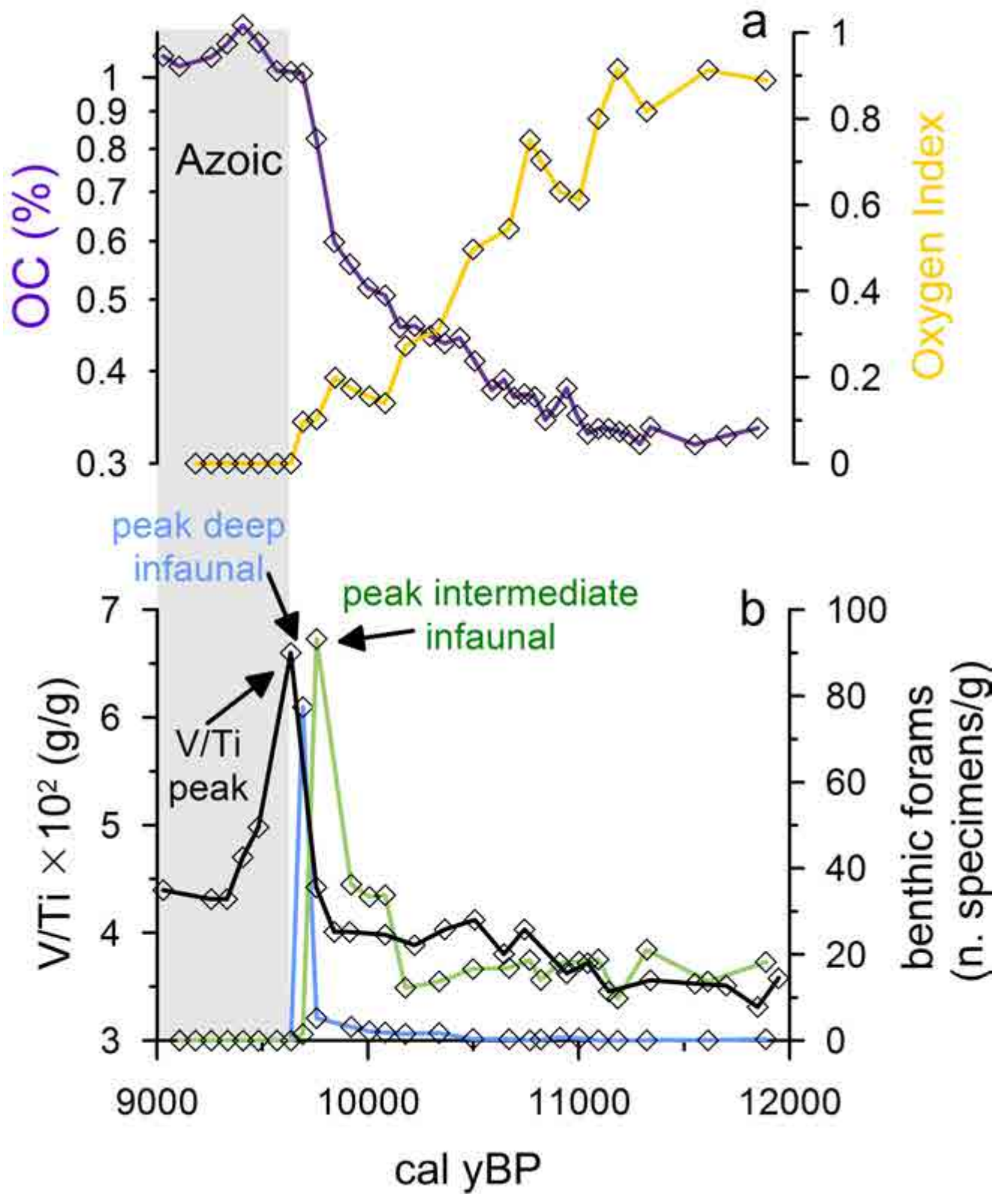


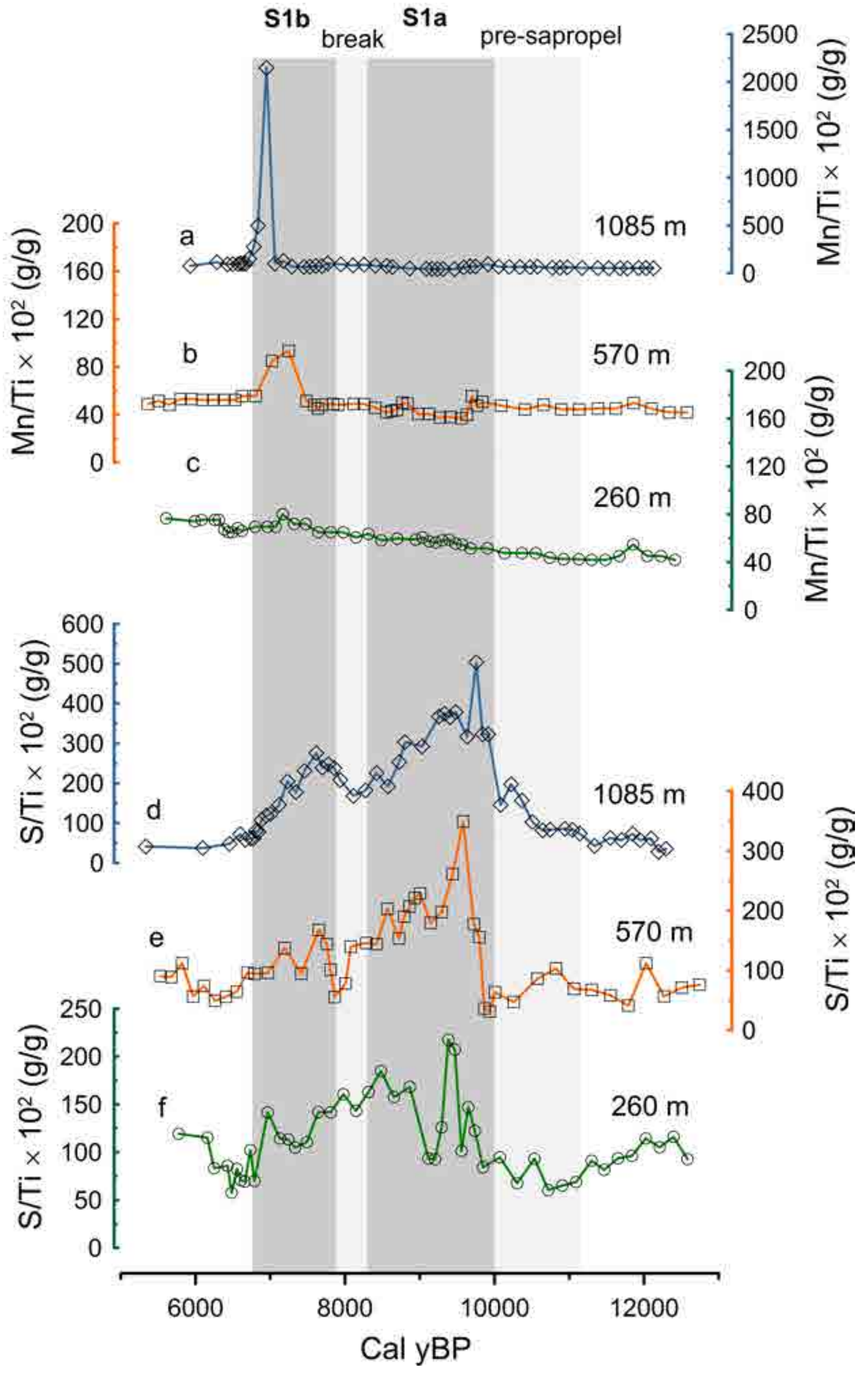


Benthic collapse Intra-S1 recolonization Benthic recovery oxygen index $<0.5$ oxygen index $>0.5$ oxygen index $>0.5$ Aegean Aegean Aegean

- Levantine

I- Levantine

- Adriatic

Adriatic

- Levantine

- Adriatic

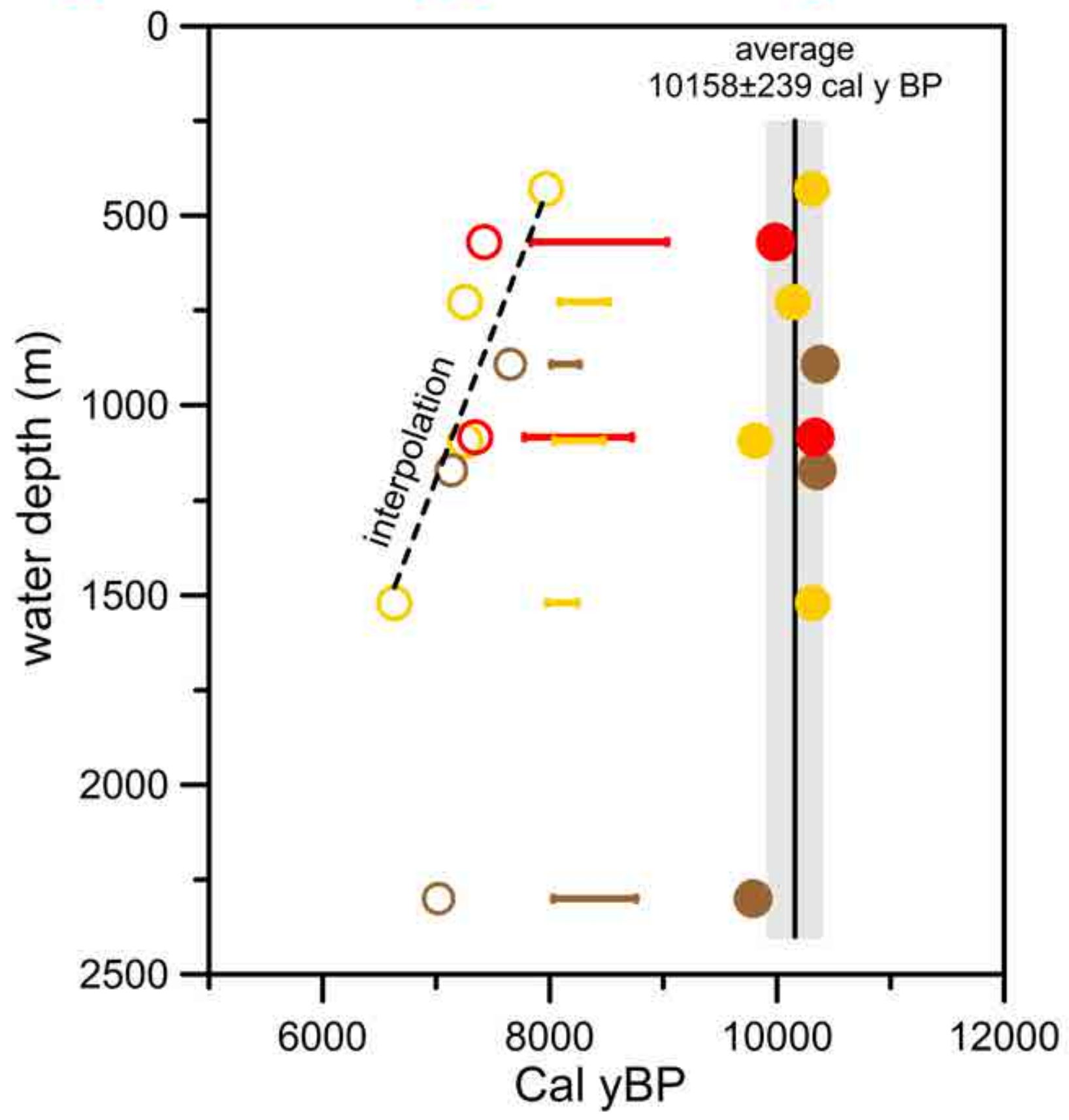


core AD91-17 (w.d. $844 \mathrm{~m}$ ) (after Capotondi et al, 1998 ,

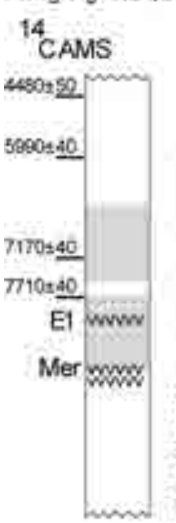

A
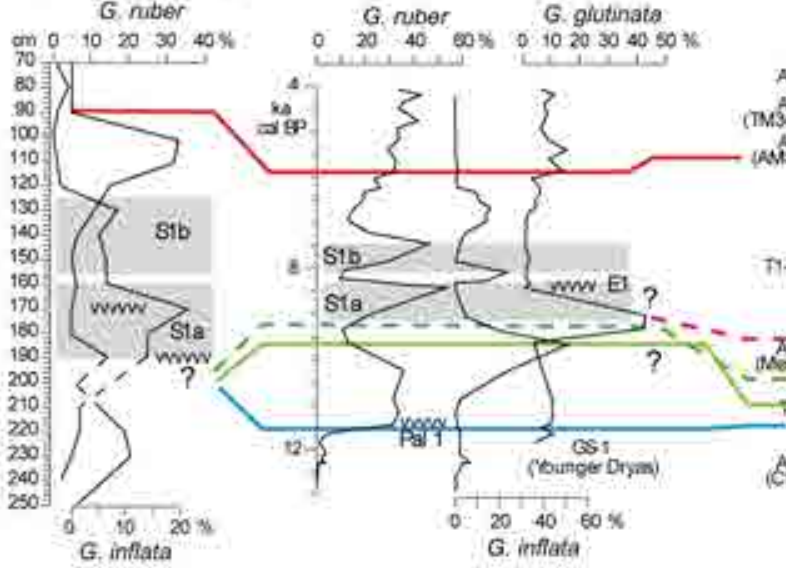

G. inflata

(C)

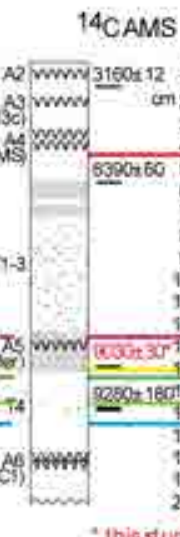

after Rohling at al , 1997 and Calanchi et al. 2008

CAMS G. nuber G. rubescens $0,102030 \%$
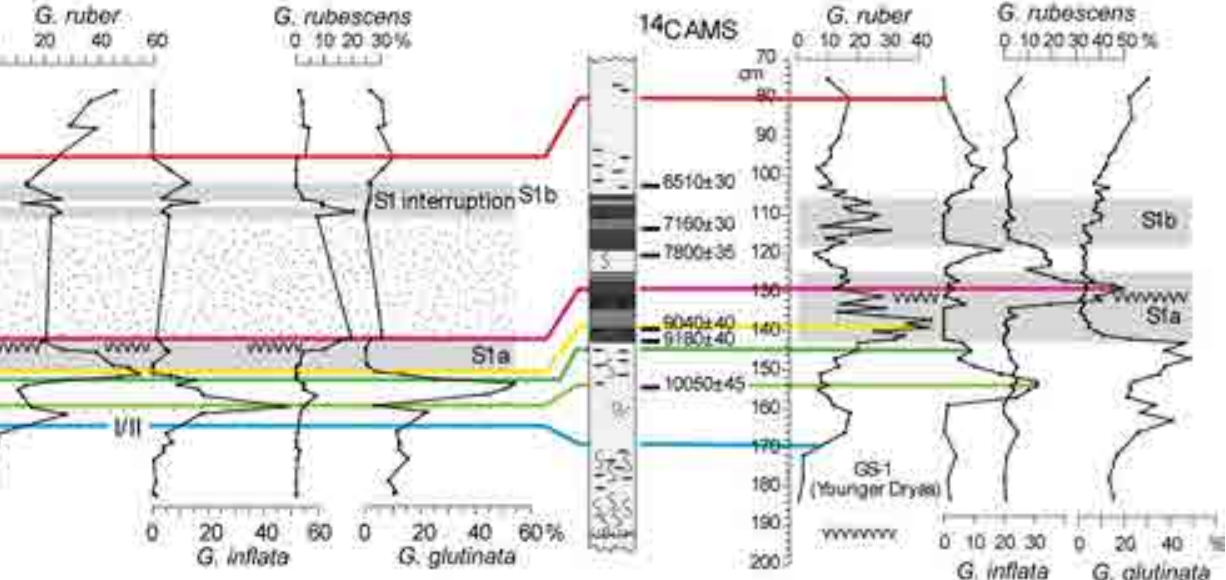

\section{B core MD90-197 (w.d. 1010 m

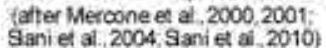

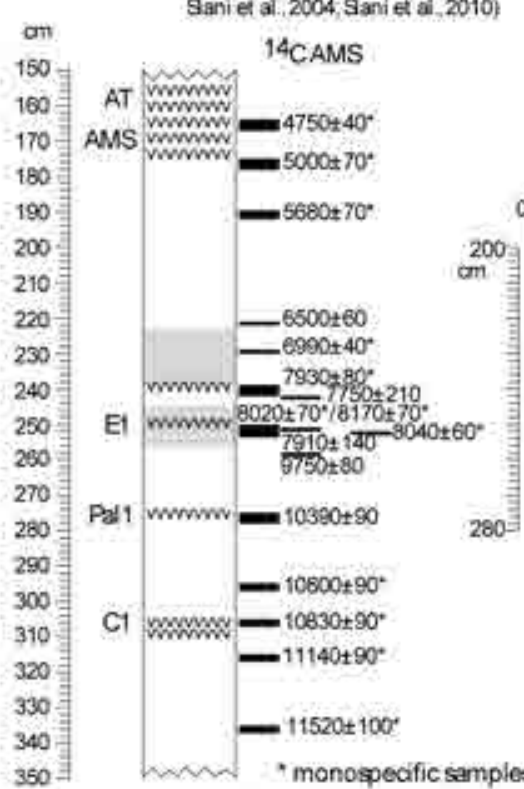

dark units ( $=$ Sapropel 1) thickness according to Mercone et a (2001)

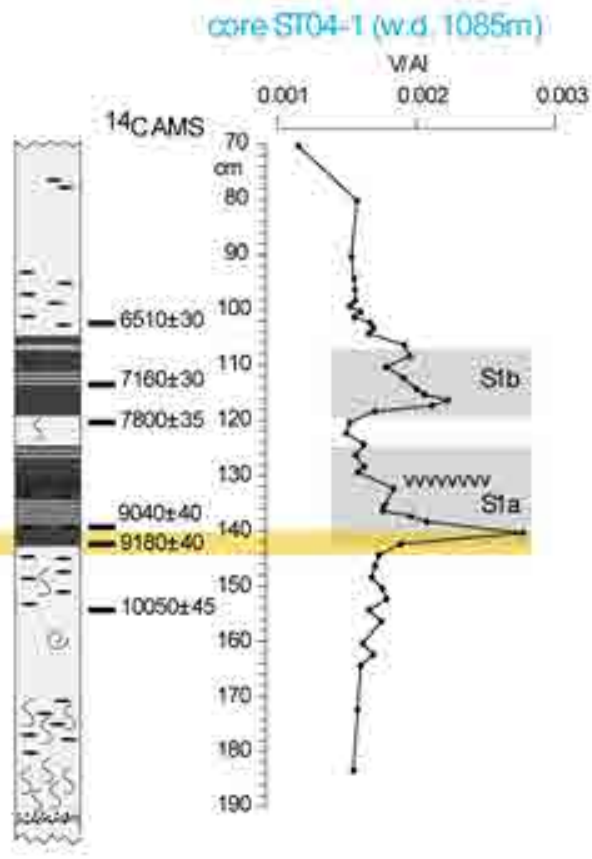

0003

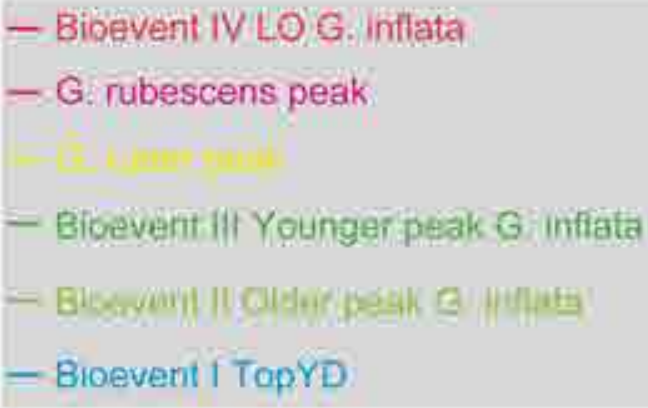

\section{Tephra layers}

$\begin{array}{ll}\text { AT } & \text { Astroni } \\ \text { AMS } & \text { Agnano Monte Soina } \\ \text { E1 } & \text { Gabellotto-Fiumebianco } \\ \text { Mer } & \text { Mercato } \\ \text { Pal1 Capo Palinuro } \\ \text { C1 Agnano Pomici Pincipali }\end{array}$

AT Astroni

C1 Agnano Pomici Principali 


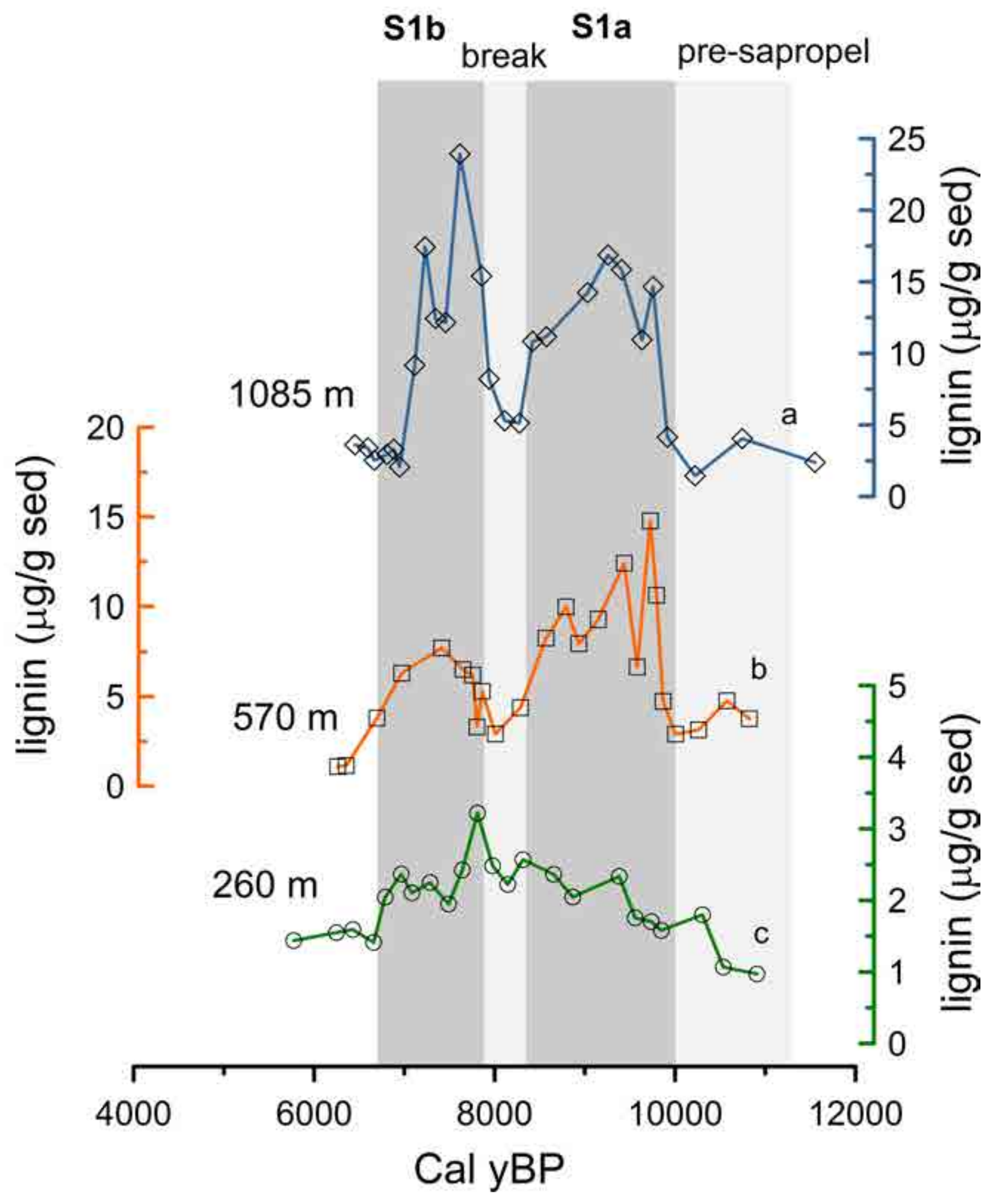


In this section, we revisit the age-depth model originally presented by Rohling et al. (1997) using Oxcal. The new model allows for random fluctuations in sediment deposition (P_sequence) and benefits of a new radiocarbon date (monospecific planktonic test, G. ruber, reference OS-127850) (Table S1). In addition to the radiocarbon tests, the model relays on well-characterized, radiocarbon dated bioevents (I,II, III, IV) as specified in the main text and Table S1. Our overarching goal is to understand whether the offset (ca. 1ky) between our results and Rohling et al. (1997) is a consequence of the age-depth model constrain. The Oxcal script used to generate the model is reported below. Particular attention was given to the agreement index which measures the coherence between the model (prior) and the observational data (likelihood).

Radiocarbon test UTC-501 (Table 1; Fig. S1,S2,S3) turned out having a low agreement index (ca. 4\%) (Fig. S3) and thus considered as an outlier. Altogether, our analysis revealed that the offset derives from this radiocarbon value being relatively young.

Table S1. Radiocarbon dates of core IN68-9

\begin{tabular}{|c|c|c|c|c|}
\hline Lab. \# & $\begin{array}{c}\text { depth } \\
(\mathrm{cm})\end{array}$ & Sample & $\begin{array}{c}{ }^{14} \mathrm{C} \text { age }(\mathrm{yr} \\
\text { BP) }\end{array}$ & Source \\
\hline UTC-500 & 11.5 & benthic forams & $3160 \pm 120$ & Rohling et al. (1997) \\
\hline CAMS-33373 & 43 & mixed planktic & $5880 \pm 60$ & $\begin{array}{c}\text { Bioevent IV, LO G. inflata (core RF93- } \\
\text { 30); Trincardi et al. (1996) }\end{array}$ \\
\hline UTC-1607 & 54.5 & mixed planktic & $6390 \pm 60$ & Rohling et al. (1997) \\
\hline OS-127850 & 137.5 & Globigerinoides ruber & $9030 \pm 30$ & this study \\
\hline Poz-16142 & 143 & mixed planktic & $9360 \pm 50$ & $\begin{array}{l}\text { Bioevent III, Younger peak G. inflata } \\
\text { (core SA03-1); Favaretto et al. (2008) }\end{array}$ \\
\hline Poz-16144 & 155 & mixed planktic & $9860 \pm 60$ & $\begin{array}{l}\text { Bioevent II, Older peak G. inflata (core } \\
\text { SA03-1); Favaretto et al. (2008) }\end{array}$ \\
\hline UTC-501 & 156.5 & benthic forams & $9280 \pm 180$ & Rohling et al. (1997) \\
\hline CAMS-16305 & 162.5 & mixed planktic & $10450 \pm 90$ & $\begin{array}{c}\text { Bioevent I, Top YD (core CM92-43); } \\
\text { Asioli et al. (2001) }\end{array}$ \\
\hline UTC-502 & 241.5 & mixed planktic & $13100 \pm 200$ & Rohling et al. (1997) \\
\hline
\end{tabular}




\section{Oxcal script}

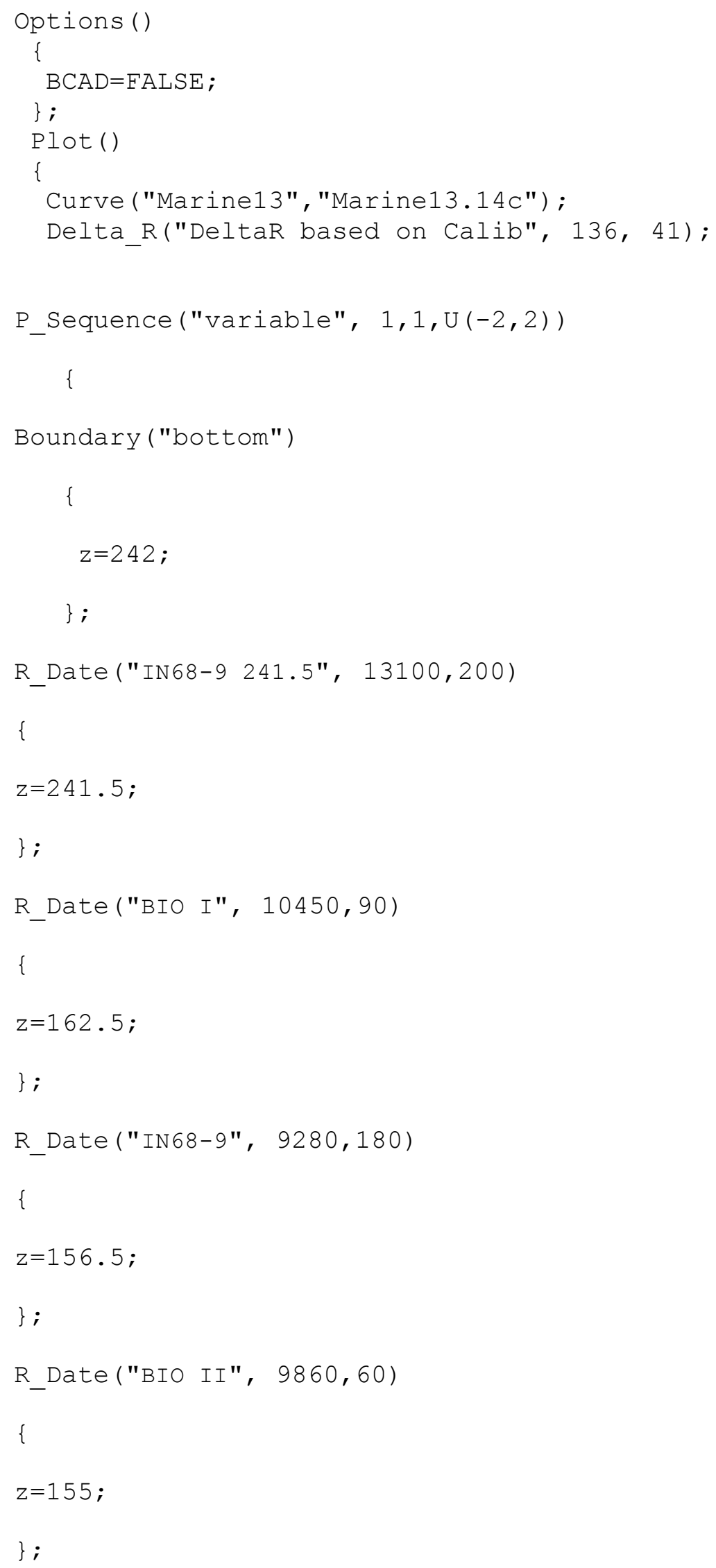




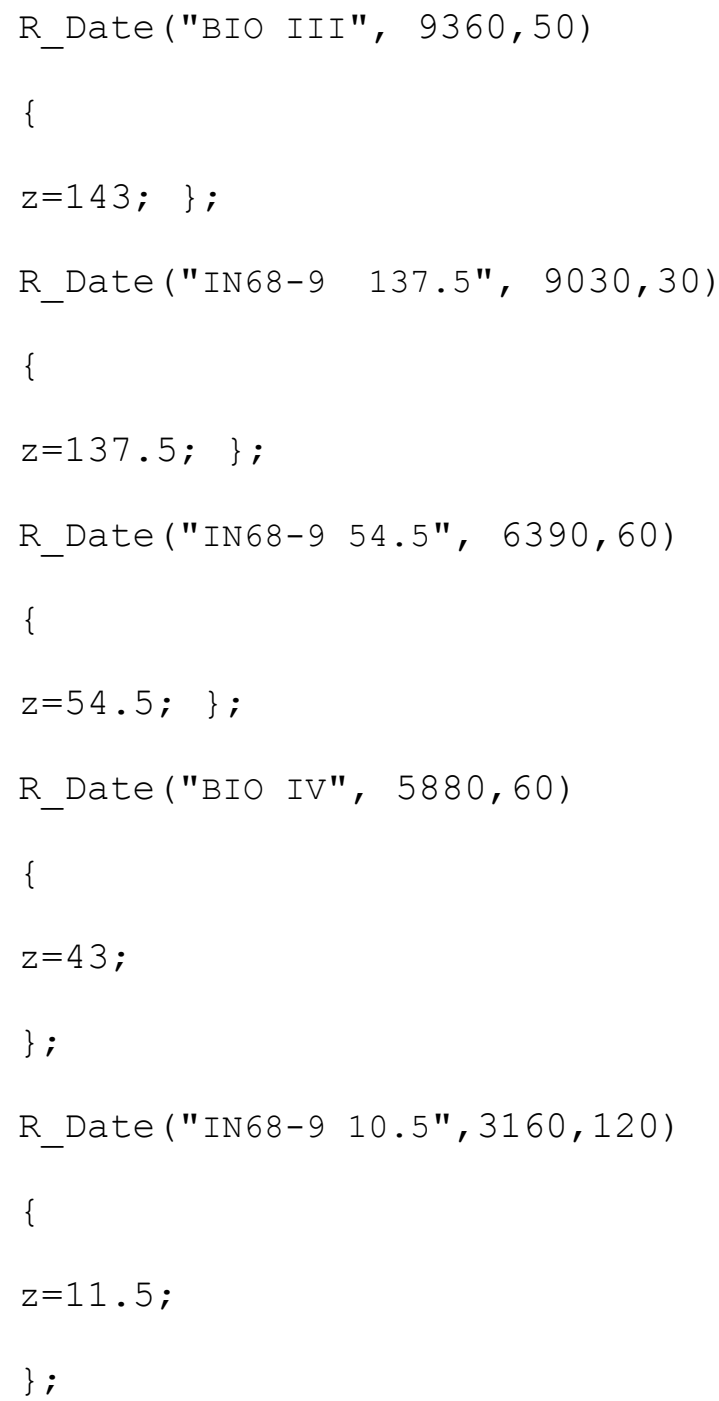




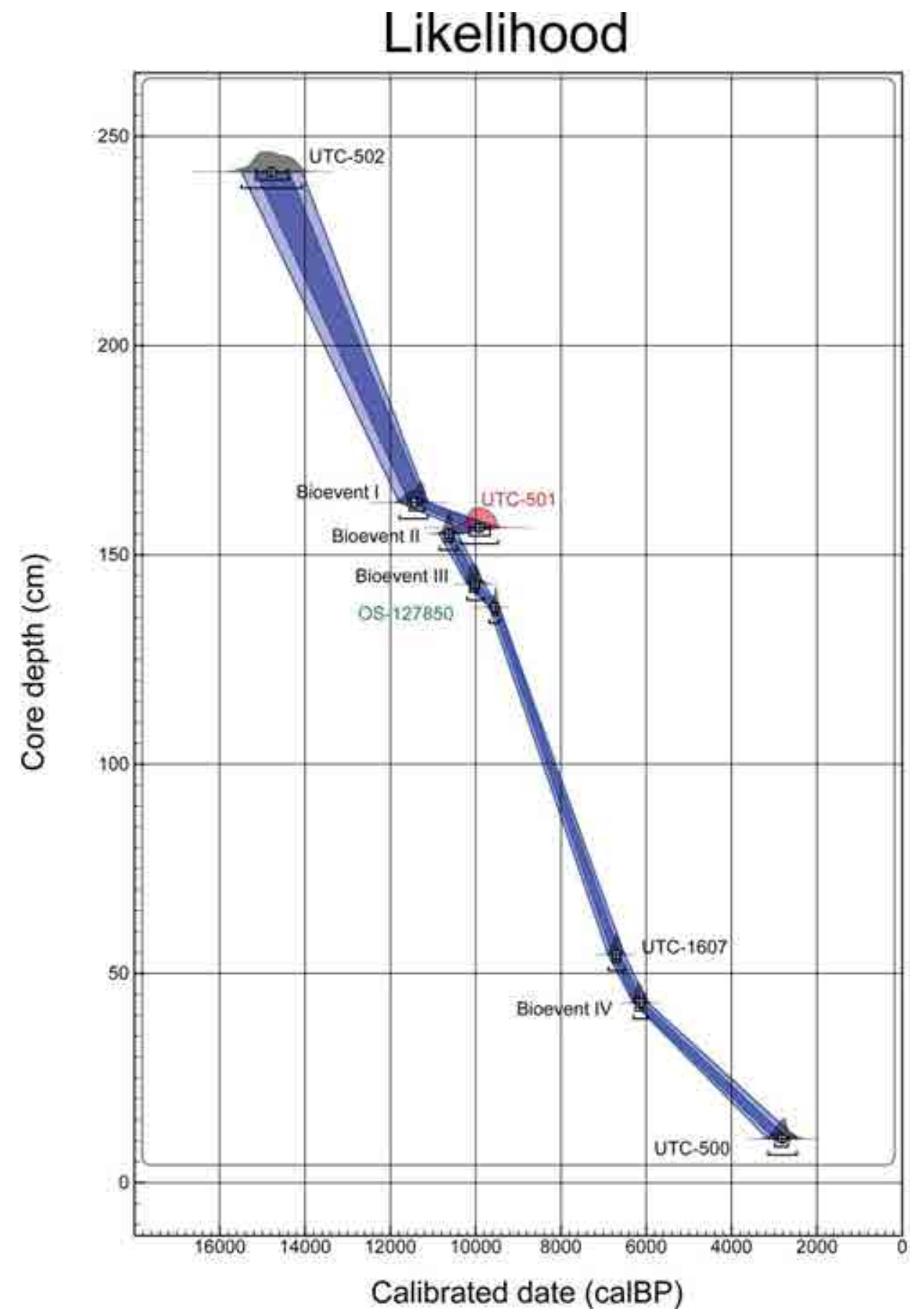

Fig. S1. Likelihood probability distributions of calibrated radiocarbon dates Light and dark blue show $1 \sigma$ and $2 \sigma$, respectively. 


\section{Posteriori}

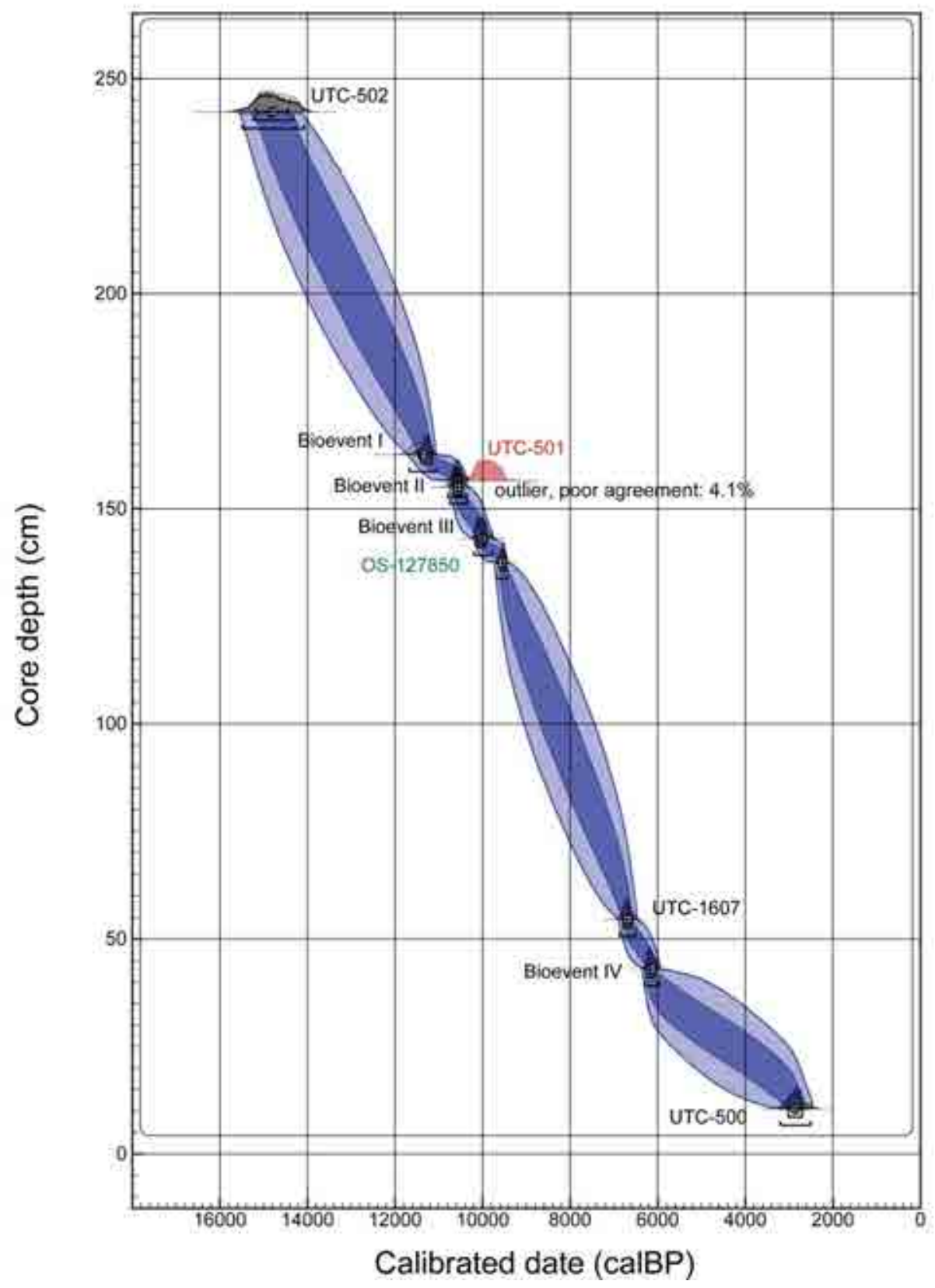

Fig. S2. Posterior probability distributions of calibrated radiocarbon dates Light and dark blue show $1 \sigma$ and $2 \sigma$, respectively 


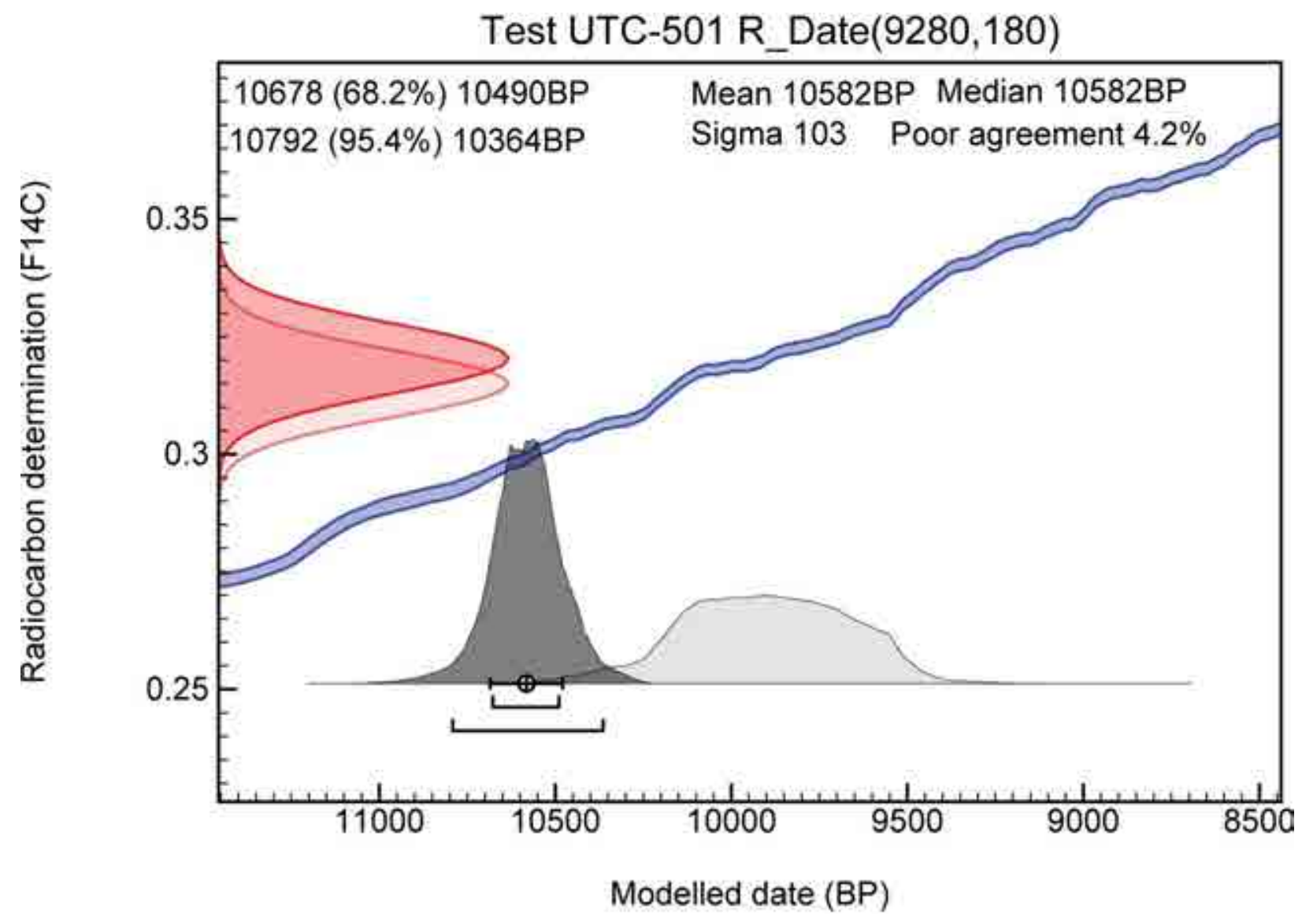

Fig. S3. Posterior probability distribution (dark grey) vs likelihood probability distribution (light gray) of test UTC-501. 
Asioli, A., Trincardi, F., Lowe, J., Ariztegui, D., Langone, L., Oldfield, F., 2001. Submillennial scale climatic oscillations in the central Adriatic during the Lateglacial: palaeoceanographic implications. Quaternary Science Reviews 20, 1201-1221.

Favaretto, S., Asioli, A., Miola, A., Piva, A., 2008. Preboreal climatic oscillations recorded by pollen and foraminifera in the southern Adriatic Sea. Quaternary International 190, 89-102.

Rohling, E., Jorissen, F., De Stigter, H., 1997. 200 year interruption of Holocene sapropel formation in the Adriatic Sea. Journal of Micropalaeontology 16, 97-108.

Trincardi, F., Cattaneo, A., Asioli, A., Correggiari, A., Langone, L., 1996. Stratigraphy of the late-Quaternary deposits in the central Adriatic basin and the record of short-term climatic events. MEMORIE-ISTITUTO ITALIANO DI IDROBIOLOGIA 55, 39-70. 
The Adriatic S1 is coeval with the Eastern Mediterranean S1 deposits

The Adriatic S1 onset is synchronous with the shutdown of the NAdDW

African monsoons weakened the LIW which in turn hampered the NAdDW formation 